\title{
Networks of Intergovernmental Organizations and Convergence in Domestic Economic Policies
}

\author{
Xun CaO \\ University of Essex
}

\begin{abstract}
We studied three potential causal mechanisms through which network dynamics of intergovernmental organizations (IGO) might cause convergence in domestic economic policies. First, IGO networks facilitate policy learning by providing relevant information. Second, they encourage policy emulation by creating a sense of affinity among countries that are closely connected by IGO networks. Finally, some powerful IGOs "coerce" their member states to adopt certain policies. We used causal modeling to test the relationships between different types of IGOs (and the causal mechanisms to which they mostly correspond) and policy convergence. The findings demonstrate the important roles played by salient IGOs such as the WTO, the EU, and the OECD, with each of them having a strong converging effect on their member states' domestic economic policies. More interestingly, we find that the cumulative effects of multiple layers of even the weakest types of IGOs have strong causal effects on states' domestic policies. Indeed, the shared memberships in IGOs with economic functions and with the minimal level of institutional capacity are not only statistically associated with, but also have converging causal effects on, countries' domestic policies. This supports the information-driven policy learning mechanism. The emulation mechanism in which IGO networks create a sense of affinity and therefore facilitate policy diffusion and convergence, on the other hand, is not supported by empirical analysis.
\end{abstract}

\section{Policy Convergence and IGO Networks}

Since the late twentieth century, the worldwide spread of liberal economic policies has become one of the defining features of economic globalization. The recent literature on policy diffusion indicates that connections at the international level, such as trade, foreign direct and portfolio investment, and ties of common language, religion, and colonial legacies, facilitate the diffusion of liberal policies and international standards (Guler, Guillen, and MacPherson 2002; Elkins, Guzman, and Simmons 2006; Lee and Strang 2006; Prakash and Potoski 2007). Dynamics in the networks of trade and transnational capital flows, especially the competition among countries targeting the same exports markets and

Author's note: The author wants to thank Yoram Haftel, Aseem Prakash, Michael Ward, Erik Wibbels, and three anonymous reviewers and editors of the $I S Q$ for their excellent comments and suggestions. The author also wants to thank Paul Ingram for kindly sharing the IGO function and capacity data. Data and $\mathcal{R}$ code for this research can be found at http://privatewww.essex.ac.uk/ caox. 
sources of foreign investments, often engage countries in a "race to the bottom" to liberal economic policies (Simmons and Elkins 2004). Meanwhile, proximity in culture and language also causes policy diffusion among peer countries as it facilitates policy learning and emulation (Simmons, Dobbin, and Garrett 2006). While the networks of trade and capital flows and cultural ties have been closely studied as the media of policy diffusion, we know little about the relationship between the connections created by the networks of intergovernmental organizations (IGO) and domestic economic policy convergence.

We live in a world in which even the most remote corner of the planet can hardly escape global connections (Barabasi 2002; Watts 1999). A connected world brings not only opportunities but also conflicts between old traditions and the new rules of the market. The co-existence between the Olive Tree and the Lexus (Friedman 2000) raises interesting questions: as the growing integration of the market breaks the niches of old traditions, how far should we go into a free market economy where opportunities and wealth coexist with risks and a lack of protection and sense of belonging? National governments are confronted with similar questions. As the communist, socialist, and Keynesian experiments failed eventually, and the idea of import-substituting industrialization has also been proved counter-productive, joining the network of the global economy becomes the only option left. The whole world seems to be heading to a more and more market-oriented economy, but how much do national governments have to adopt new economic policies and institutions to survive and possibly thrive? Are we all heading in the same direction of efficiency-mandated minimalism? Various scholars have been trying to provide answers to these questions. In the field of comparative and international political economy, the fault line is drawn between those who believe in the persistence of national varieties and those who hold a convergence view. The former group tends to emphasize how various factors internal to domestic politics and economies can resist the pressure of economic forces of globalization, so that there is still room to move (Garrett and Lange 1989; Garrett 1998; Hall and Soskice 2001; Kitschelt 2001). The latter group points to the structural power of an integrated global market, especially that of transnational capital, to discipline states (Andrews 1994; Cerny 1995; Rodrik 1997).

This convergence-divergence debate has been a heated topic over the past few decades. Convergence can be considered as a process wherein distinctive domestic institutions and economic policies fade over time, giving way to common economic structures the efficiency and universality of which produce superior strength in the market (Berger and Dore 1996). Divergence, on the other hand, refers to persistent diversity of national policies and institutions. The issue at stake often is whether and how forces of economic globalization overtake domestic forces in the processes of national policy and institution making. With regard to the forces of economic globalization, most research to date has been focusing on the flows of labor, capital, goods, and services. Particularly, trade openness and capital market openness have often been the focus of research, and have been linked to many aspects of macro-economic policy and institutional changes, such as social welfare policies (Cameron 1978; Burgoon 2001; Garrett and Mitchell 2001), industrial subsidies (Zahariadis 1997, 2001), and monetary and fiscal policies (Mosley 2000; Wibbels and Arce 2003; Basinger and Hallerberg 2004). However, the link between connections in the networks of intergovernmental organizations (IGOs) and the convergence-divergence phenomenon in domestic economic policies has not been systematically studied in the field of comparative and international political economy.

In sociology, the world polity literature has shown that the institutionalization of the increasingly dense global network of states and international organizations is altering the landscape of world politics (Beckfield 2003). Recent research 
indicates that involvement in international organizations shapes state policy in many domains, such as the expansion of mass education (Meyer, Ramirez, and Soysal 1992), the change in discourse of environmental protection (Frank 1997), the diffusion of science policy organization (Finnemore 1993), and the development of western welfare states (Strang and Chang 1993). Recognizing the difference between international institutions and intergovernmental organizations, our goal in this paper is to provide a systematic test of how the networks of formal intergovernmental organizations (IGOs) affect policy convergence in domestic economic policies. ${ }^{1}$ Recent studies show that connections in the IGO networks matter for policy diffusion and convergence in domestic economic policies: the more IGOs shared by two countries, the more similar their domestic economic policy configurations (Cao 2006). However, we know little about the exact causal mechanisms through which IGO networks affect domestic policy outcomes. Borrowing insights from recent studies on social interactions and policy diffusion (Granovetter 1985; Uzzi 1996; Simmons and Elkins 2004; Simmons et al. 2006), we consider three mechanisms through which IGO networks might affect domestic policy outcomes: coercion, learning (by the exchange of information), and emulation (based on a sense of affinity). The latter two mechanisms might constitute what we consider a socialization process.

\section{Mechanisms of Policy Convergence: Coercion, Learning, and Emulation}

The first mechanism through which IGOs might affect domestic policy outcomes is coercion. Simmons, Dobbin, and Garrett discuss potential mechanisms of the diffusion of neoliberalism and point out that "One prominent explanation for the spread of economic and political liberalism involves a distinctively antiliberal mechanism: coercion" (Simmons et al. 2006). Coercive diffusion of policies involves power asymmetries that the strong exploit to impose their policy preferences on weaker countries. Meanwhile, there are different soft versions of coercion, such as policies of powerful governments constituting focal points in policy coordination games with multiple equilibria, and softer still, powerful countries may be closely aligned with theories, information, or ideas that favor particular policy moves, such as liberalization. So far, powerful states have been the focus in the coercion story, but certain types of IGOs could also exert coercive power on their member states, sometimes even on non-member states. ${ }^{2}$ The EU is often quoted as a typical example and few deny the impact of the Stability and Growth Pact on EU member states' fiscal policies. Other IGOs that might have coercive power with respect to member states could include the GATT/WTO, the IMF, and the OECD.

There are some controversies and potential weaknesses for the coercion argument above. Coercion, by definition, implies an asymmetric power relationship wherein states would rather not adopt certain policies in the absence of coercive power. Given the fact that almost all the IGOs are voluntary organizations, it is hard to imagine why weak states would choose to join an IGO that can exercise coercive power over its member states in the first place. Gruber (2000) provides an interesting answer to this question: the "go-it-alone-power" of (major) existing member states. Once most of the neighboring countries are already in an IGO, the costs of being left behind are so high that a country has to follow up even though being a member makes the country subject to a series of domestic

\footnotetext{
${ }^{1}$ Institutions are often defined by formal and informal norms, patterns, conventions, and procedures that shape economic, political, and social life (North 1990). IGOs are organizations that meet regularly, are formed by treaty, and have three or more states as members (Pevehouse, Nordstrom, and Warnke 2003).

${ }^{2}$ See Goldstein, Rivers, and Tomz (2007) for a study on how the WTO affects non-member states' trade policies.
} 
policy commitments. For example, the EU imposes an upper limit on budget deficits and the WTO requires developing countries to liberalize their banking sector. The second point one might question regarding the coercive power of IGOs is whether the coercive power actually comes from the IGO itself or from dominant members of the IGO. This is a long-time debate in international relations involving the basic question of whether international institutions take on a life of their own or whether they are just tools used by powerful states (Mearsheimer 1994). Similar debate in the EU context concerns the different understandings of regional integration between intergovernmentalism and neofunctionalism. It is beyond the scope of this research to engage theoretically in this grand debate. What we are interested in is whether there is, first, an association between countries' domestic policy outcomes and some IGO memberships that might convey coercive power, and second, whether we can establish a causal relationship between the two.

The second mechanism connecting IGO networks and domestic policy outcomes is learning and we focus on learning from an information perspective. As Simmons, Dobbin, and Garrett point out, one of the central issues of any learning process is how the data are collected (Simmons et al. 2006). Like investors in the financial market who face the problem of costly information gathering (Calvo and Mendoza 2000), policymakers and other players of the policy-making processes cannot collect and process all information. Therefore, cognitive shortcuts are often needed to channel the attention to some sources of information while ignoring others. In other words, information travels through some shortcuts or bridges connecting actors. Some examples of these bridges might include communication networks and personal contacts of officials in the case of policy diffusion. Indeed, in sociology and organizational studies, a large literature exists and shows that a range of formal and informal connections between actors smooth exchange between them (Granovetter 1985; Uzzi 1996; DiMaggio and Louch 1998). Ingram (2005) nicely summarizes this literature and points to two types of studies that are most relevant to our understanding of policy learning in the context of IGO networks. These two bodies of literature include studies of diffusion of ideas, innovations, and practices through networks (Davis 1991; Burns and Wholey 1993; Kraatz 1998), and studies on learning curve that reveal that learning from other organizations' experiences is facilitated by network connections (Darr, Argote, and Epple 1995). These works point out that network connections, such as ownership of the same franchisee and interlocking directorates of large corporations, facilitate knowledge transfer and smooth the exchange of information, and therefore the diffusion of ideas, innovations, and practices.

However, as Ingram (2005) points out, one central question unanswered in the literature "regarding interorganizational learning is "just how does it happen?" "This is also an important question we need to address in the context of IGO networks facilitating policy learning. At the international level, networks of intergovernmental organizations, especially those with economic purposes, can serve as important channels for the spread of information about economic policies among their member states. One can easily find examples where salient IGOs promote the spread of certain kinds of information in order to cause policy transmission at the domestic level, such as the IMF's effort to disseminate lessons of economic liberalization and that of the Council of the European Union

\footnotetext{
${ }^{3}$ Simmons et al. (2006) identify three different approaches for policy learning: political science's focus on social knowledge, Bayesian learning by updating prior belief with new data, and channeled learning facilitated by network connections in sociology and organizational studies. The policy learning mechanism in this manuscript falls into the third approach which focuses on how network connections facilitate diffusion of ideas, innovations, and practices. One contribution of this research is to demonstrate that even the weakest types of IGOs facilitate policy diffusion.
} 
to promote liberalization in the electricity and gas sector in Europe. What is empirically undetermined in the literature is the cumulative effect of multiple layers of "weak" IGOs that might also cause policy changes. Most of these IGOs, such as the International Bureau of Commercial Statistics and the Arab Fund for Economic and Social Development, do not have the same level of resources and institutional capacity as the IMF and the EU. However, Darr, Argoate, and Epple's research on 36 pizza stores in Southwestern Pennsylvania points out processes of interorganizational learning that do not require a lot of resources and institutional capacity. They show convincingly that first, regular communications between organizations increase the opportunity of knowledge sharing, and second, meetings provide opportunities for face-to-face contact that facilitates the diffusion of ideas, innovations, and practices (Darr et al. 1995). ${ }^{4}$ Therefore, IGOs, even the weak ones, spread relevant information about economic policies and serve as channels of connections for the flow of ideas and information through communications and meetings among member states. Connections often then create commonalities in viewpoints and shared languages. By providing multiple dimensions of understanding of relevant policies, it is likely that the cumulative effect of a dozen of even the weakest IGOs might trigger policy changes in similar directions and therefore cause policy convergence among countries that are densely connected in the networks of these IGOs.

The third mechanism is emulation and here we focus on reference group theory. From this perspective, actors emulate the behavior of their self-identified peers, even when they often cannot ascertain that doing so will in fact be in their best interests (Simmons et al. 2006). If states choose to emulate, they can simply pick policies of the best practice. But as policymakers are getting more and more complicated, the so-called best practice has to be context-sensitive: what works in wealthy developed countries might be a policy disaster for lots of developing countries. Indeed, the source of information matters for its persuasiveness (Johnston 2001). Information from in-group members is often more convincing, and therefore is more likely to be considered persuasive, than that from out-group members. Especially when there is conflicting information about certain policy and/or when there are too many policy alternatives that it is already beyond the cognitive limits of real world actors to look at everything, policymakers might just choose to emulate policy choices of those "in-group" members. Group membership involves the identification of peers and often implies "liking." Liking increases with more exposure, contact, and familiarity (Johnston 2001). The selfidentification process involves long-term interactions along different dimensions, not only economic, but also social and cultural, that might create a sense of affinity among countries.

Common language, culture, and religion are often important for countries to identify themselves with peer countries. In this research, we move beyond these usual suspects of connections that are expected to cultivate the sense of affinity. We focus on IGOs, especially those with social and cultural purposes, such as the African Cultural Institute, the Community of Portuguese-Speaking Countries, and the Latin Union. We expect that they help to create a sense of affinity among member states that in turn facilitates policy emulation. Relationship governs exchange. We know that there are at least two dimensions of relational governance that are relevant for IGO networks: utilitarian and affective. The utilitarian dimension is more relevant for the policy learning mechanism as a country estimates pros and cons of a certain policy choice based on available information. The affective dimension, on the other hand, is based on trust,

\footnotetext{
${ }^{4}$ Darr, Argote, and Epple (1995) also discuss the role of personal acquaintance created by network connections as it creates the sense of empathy, familiarity, and trust that smooth the exchange of information. This is relevant to the mechanism of emulation that we are going to discuss.
} 
empathy and sympathy (Granovetter 1985). IGOs with social and cultural purposes often create this sense of "affinity" among their member states and are likely to facilitate policy emulation and therefore convergence among member states. ${ }^{5}$

We have surveyed three possible mechanisms through which IGO networks might affect member states' domestic policy outcomes. Coercion focuses on the capacity of an individual IGO to shape policy outcomes of its member states. Having a sufficient level of institutional capacity, a single IGO, such as the EU, can impose policy imperatives and effectively change domestic policy outcomes of its member states. Therefore, we should be able to observe policy convergence among EU member states. However, we know that there are few IGOs that might have this level of institutional capacity, especially in the realm of domestic economic policies. The EU, the GATT/WTO, and the OECD are some of potential candidates we consider in this paper. The other two mechanisms, that is, learning and emulation, on the other hand, involve interconnected, dense IGO networks. None of these IGOs has to have a coercive power over member states' decisions, but the cumulative effects of multiple IGO networks might facilitate the flow of relevant information and create a sense of affinity and therefore have effects on member states' decisions. Ingram, Robinson, and Busch (2005), discussing how IGO connections might affect bilateral trade, point out that

\begin{abstract}
... important interactor relationships are "thick," with multiple dimensions of understanding and influence (Uzzi 1996). As for institutional interdependence, even a small international transaction might depend on the existence of dozens of IGOs that might help a buyer find a seller, coordinate transportation and communication between the seller and buyer, provide them with standardized measurements upon which to base negotiations, and, finally, convert currencies and clear a check. (829)
\end{abstract}

Issues of multiplexity and interdependence necessitate consideration of a broad set of IGOs, at least as a starting point. In the anarchy of international relations, states are actually connected by large amounts of IGOs. If learning and/or emulation through IGO networks really affect domestic policy outcomes, we should be able to observe more convergence among countries that are closely connected by relevant IGO networks than among countries that are loosely connected. Moreover, the functions of IGOs provide a clue to differentiating learning from emulation. IGOs with social and cultural purposes do not provide information on economic policies, neither do they directly facilitate interstate interactions in the economic area, but they might help create a sense of affinity among member states which increases the chance of policy emulation. IGOs with economic purpose convey more information about economics and policies and therefore can be linked to the learning mechanism; at the same time, they might also help cultivate trust and sympathy among states and facilitate policy emulation.

There are other alternative mechanisms through which intergovernmental organizations might affect domestic politics. First, international organizations can help solve collective action problems such as collaboration (Prisoners'

\footnotetext{
${ }^{5}$ We acknowledge that our discussion on the socialization processes does not fully specify who are the realworld actors and how they interact in the processes of learning and emulation exactly. One reason is that we are dealing with a large number of IGOs with different memberships and agendas in a large- $n$ study. Indeed, one reviewer raised important questions: first, is the "unit" that participates in a weak organization the same "unit" that later determines domestic economic policies; second, even assuming that members of one IGO create a socialized community, can one really assume that this can directly influence policymaking in other ministries of the government? We understand that these questions point to one weakness of this paper (and lots of other large- $n$ studies on policy diffusion) and one important direction for future research. To answer these questions, we need to conduct process-tracing research in case studies that focus on individual IGOs in future research.
} 
Dilemma) and coordination (existence of multiple Pareto-optimal equilibria, such as the Battle of Sexes) among states (Keohane 1984; Garrett and Weingast 1993). Moreover, domestic actors might have strong incentives to delegate domestic policymaking to international organizations. High barriers to policymaking in domestic institutions might induce delegation to international institutions to break the deadlock in domestic politics. The time-inconsistent preferences of domestic political actors might also induce transference of policymaking from domestic to international level. ${ }^{6}$ These mechanisms provide great insights into the study of international institutions upon which actors' expectations converge. However, the study of these mechanisms often requires detailed research on specific international institutions and/or regimes (Krasner 1983), often done by case studies. In this research, we chose to conduct a large- $n$ study of network group behavior in the networks of formal intergovernmental organizations. ${ }^{7}$

\section{Linking IGO Function and Capacity to Convergence Mechanisms}

In order to test the three different mechanisms, we need to differentiate different types of IGOs. Most of the large- $n$ studies involving IGOs do not differentiate between different types of intergovernmental organizations: IGOs with little institutional capacity and purely socio-economic purposes, such as the African and Malagasy Council for Higher Education and the African Foundation for Research and Development, are treated equivalently with those with much stronger institutional capacity and military and economic purposes such as NATO and the GATT/WTO. Boehmer, Gartzke, and Nordstrom (2004), Ingram et al. (2005), and Bearce and Bondanella (2007) are three recent exceptions to this tradition of undifferentiated treatment of IGOs. They provide refined analyses on the links between IGOs and peace, IGOs and trade, and IGOs and memberstate interest convergence. These works reveal that the controversies and mixed findings in terms of the links between IGOs and other political and economic phenomena can often be solved by differentiating between different types of IGOs. Rather than treating every IGO as equal, they categorize IGOs by their functions and institutional capacity to implement certain policies and therefore affect member states' behaviors. ${ }^{8}$

According to the levels of IGO capacity to affect member states' behavior, one can categorize IGOs as being minimalist, structured, and interventionist. Minimalist IGOs refer to those that have plenary meetings, committees, and possibly a secretariat, but without an extensive bureaucracy beyond research, planning, and information gathering. The definition suggests that minimalist IGOs have no institutional capacity to coerce and therefore forcibly affect member states' policy choices. Structured IGOs, on the other hand, have a stronger capacity; they contain structures of assembly, executive (non-ceremonial), and/or bureaucracy to implement policy, as well as formal procedures and rules.

Interventionist IGOs contain mechanisms for mediation, arbitration, and adjudication, and/or other means to coerce state decisions (such as withholding loans or aid), as well as means of enforcement of organizational decisions and norms. These IGOs have the highest level of institutional capacity to affect member states' behavior, and therefore might provide a test of the coercive mechanism. Minimalist IGOs, on the other hand, provide a test of socialization

\footnotetext{
${ }^{6}$ See, for example, the Central Bank Independence literature (Bernhard, Broz, and Clark 2002).

7 There is another alternative hypothesis, that is, convergence appears because of a liberalization trend. This trend of convergence might be simply a function of some cultural norms which operate without reference to specific network mechanisms. We control this alternative hypothesis in the empirical analysis. We thank one reviewer for pointing out this important alternative hypothesis.

${ }^{8}$ The author wants to thank Paul Ingram for kindly sharing the IGO function and capacity data.
} 
mechanisms of learning and emulation. Since these minimalist IGOs have no institutional capacity to coerce states, if they ever matter for states' domestic policy outcomes, they have to do so in "soft" ways, such as providing relevant information for economic policies and helping to create the sense of affinity among member states. Information sharing in turn facilitates policy learning and the sense of affinity also increases the chance of policy emulation. Structured IGOs, however, are situated in a gray area. They have lower levels of capacity than interventionist IGOs, they might affect domestic policy outcomes by both coercion and socialization and there is no easy way to differentiate among them in a large- $n$ study like this. We therefore focus on IGOs at the two ends of the institutional capacity continuum.

Besides IGOs' institutional capacity, different IGOs have different functions. Ingram et al. (2005) broadly categorize IGOs as four different groups based on their goals and functions: general purpose, military and political, economic, and social and cultural. The latter two categories can be further broken down to three subcategories respectively:

- General purpose

- Military and political

- Economic:

- Monitoring, surety, and general economic

- Standardization and harmonization

- Cooperation and development

- Social and cultural:

- Environmental

- General

- Education and research

There are 494 IGOs in the data covering IGOs that existed between 1950 and 2000. Since our analysis of the convergence-divergence phenomena focuses on the post Cold War period, we only considered IGOs that existed after $1990 .^{9}$ This reduces the total number of IGOs in our sample to 383 . We provide a summary of IGOs grouped by functions and capacity in Table 1 . The columns of the table group IGOs by their institutional capacity, or what Ingram et al. (2005) call "structure." The rows of Table 1 capture IGO functions. From the Table, we can see that there are relatively few IGOs that are categorized as "interventionist": they represent slightly higher than $10 \%$ of the total IGO population, that is, 39 out of 383 total IGOs in the 1990-2000 period. At the same, about $60 \%$ of the IGOs are minimalist ones, that is, 227 out of $383 .{ }^{10}$ We choose to put aside the structured IGOs, that is 117 out of the total 383, for "purer" tests of convergence mechanisms.

Countries are connected by multiple networks of IGOs. For instance, the average number of bilateral IGO connections for 2000 is about 43. The effects of IGO networks on member states' domestic policy choices might go through different causal mechanisms. Coercion mostly involves IGOs with a strong capacity to restrain or even intervene in states' behavior. Learning and emulation, on the other hand, do not need to rely on IGOs with a strong institutional capacity. They are often based on cumulative effects of multiple layers of IGO networks that provide numerous dimensions of understanding and influence (Uzzi 1996). Linking IGO functions and institutional capacities to network convergence

\footnotetext{
${ }^{9}$ We only consider the post-Cold War period not only because of the problem of locating data on policy convergence before 1990, but also because for countries in the former Soviet bloc, the policy convergence is mostly a post-Cold War phenomenon.

${ }^{10}$ For visualizations of minimalist IGOs, see Appendix A that displays and discusses networks of minimalist IGOs with economic and social-cultural functions.
} 
TABLE 1. Categorization of IGOs by Function and Structure, 1990-2000

\begin{tabular}{lcccr}
\hline & Minimal & Structured & Interventionist & Total \\
\hline General purpose & 21 & 9 & 13 & 43 \\
Military/political & 4 & 7 & 9 & 20 \\
Economic & & & & 105 \\
$\quad$ Monitoring, surety, general & 66 & 29 & 10 & 24 \\
$\quad$ Standardization & 17 & 6 & 1 & 59 \\
$\quad$ Cooperation/development & 30 & 26 & 3 & 32 \\
Social & & & 0 & 48 \\
$\quad$ Environmental & 21 & 11 & 3 & 52 \\
$\quad$ General & 28 & 17 & 0 & 383 \\
$\quad$ Education and research & 40 & 12 & 39 & \\
Total & 227 & 117 & & \\
\hline
\end{tabular}

mechanisms, minimalist IGOs with social and cultural functions provide a perfect test of the emulation hypothesis: these IGOs do not have the institutional capacity to coerce state and they do not provide (at least directly) information about economic policies because of different IGO agendas, but they do provide an arena for socialization that might create a sense of community, trust, empathy, and sympathy among member states that in turn facilitate policy emulation (Granovetter 1985).

With regard to the learning mechanism, states' decisions to adopt certain economic policy often rely on a cumulation of different sources of relevant information, some of which, we argue, comes from IGOs with economic functions. Minimalist IGOs with economic functions are closely linked to the learning mechanism: these IGOs do not have any institutional capacity to coerce state behavior, but they might provide relevant information about economic policies that facilitate policy learning among well-connected states. However, these IGOs can also promote a sense of shared purposes among member states (by, for instance, bringing elites into contact) that in turn facilitates policy emulation. In other words, learning and emulation are not mutually exclusive mechanisms for minimalist IGOs with economic functions. ${ }^{11}$

The number of IGOs with an interventionist institutional capacity is much smaller than that of minimalist capacities. There are 39 of them from 1990 to 2000. Since we were interested in the coercion effects on domestic economic policies, we focus on interventionist IGOs with economic purposes. ${ }^{12}$ Unlike the mechanisms of learning and emulation that often rely on the cumulative effects of multiple layers of IGOs, coercion requires strong institutional capacity to restrain or even intervene in states' policymaking, and given that level of institutional capacity, one single IGO, such as the EU or the WTO, might have enough institutional capacity to change member states' policy. Therefore, we need to study the individual effects of these interventionist IGOs. As the first step, we chose to study the effects of the GATT/WTO, the OECD, and the EEC/EU. ${ }^{13}$

\footnotetext{
${ }^{11}$ We thank the reviewers for vividly pointing out the possibility of nested convergence mechanisms.

12 The only exception is the case of the EEC/EU. The EEC is categorized as an IGO with economic purposes, but the EEC became the EU in 1993. The EU is then categorized as an IGO with a political purpose. We include the EU as the successor of the EEC.

${ }^{13}$ IGOs that might be associated with the EU, such as the European Collaboration on Measurement Standards and the European Conference of Postal and Telecommunications Administrations, are considered independent IGOs and not reflected in the EEC/EU variable. We initially included the IMF, but almost all countries in the sample are IMF member states. We therefore dropped the IMF. Other IGOs with interventionist capacity and economic purposes include the Benelux Community, the European Free Trade Association, the Organization of Arab Petroleum Exporter Countries, the Permanent Court of Arbitration, the West African Economic \& Monetary Union, the Central Office for Intl Railway Transport, the Economic Community of Great Lakes States, the Economic Community of West African States, and the Inter-Government Authority on Drought Protection.
} 
TABLE 2. Linking IGO Functions and Institutional Capacity to Convergence Mechanisms

\begin{tabular}{lccc}
\hline & Coercion & Learning & Emulation \\
\hline$I G O_{\text {Economic,Interventionist }}$ & $\checkmark$ & $\checkmark$ & $\checkmark$ \\
$I G O_{\text {Economic,Minimalist }}$ & & $\checkmark$ & $\checkmark$ \\
$I G O_{\text {Social,Minimalist }}$ & & & $\checkmark$ \\
\hline
\end{tabular}

Coercion mechanism is only associated with interventionist IGOs, because by definition, minimalist IGOs do not have the resources and institutional capacity to coerce member states. However, coercion is not the only convergence mechanism associated with interventionist and economic IGOs. Indeed, these IGOs are not only capable of coercing member states, but they might provide relevant policy information (for policy learning) and they help cultivate the sense of community among member states (for policy emulation). ${ }^{14}$ In other words, the mechanisms of coercion, learning, and emulation can be considered nested capabilities for interventionist and economic IGOs.

Table 2 summarizes the links between convergence mechanisms and types of IGOs. " $\checkmark$ " indicates a theoretically expected association between a convergence mechanism and a specific type of IGO defined by function and institutional capacity. Specifically, from Table 2 we see that minimalist and social-cultural IGOs $\left(I_{G O} O_{\text {Social,Minimalist }}\right)$ induce policy convergence only through the mechanism of policy emulation. This provides us a perfect test for this network convergence mechanism. If policy emulation works, we should be able to observe a positive association between shared number of minimalist and social-cultural IGOs and policy convergence: the more minimalist and social-cultural IGOs two countries share, the more similar are their profiles of domestic economic policies.

Minimalist and economic IGOs (IGO Economic,Minimalist), on the other hand, are associated with both policy learning and policy emulation. This creates complications for the empirical analysis. We cannot simply associate minimalist and economic IGO connections to either of the two convergence mechanisms because they might both induce policy convergence according to our theoretical expectation. However, one way to differentiate the effect of policy learning from that of policy emulation is to compare the magnitude of the converging effect of minimalist and economic IGOs to that of minimalist and social-cultural IGOs: if learning induces policy convergence in addition to emulation, we should be able to observe a larger converging effect (per unit of shared IGO connection) from minimalist and economic IGOs than from minimalist and social-cultural IGOs, because every additional connection of minimalist and economic IGO is capable of inducing both policy learning and emulation, while every additional connection of minimalist and social-cultural IGO is only capable of inducing policy emulation. $^{15}$

Finally, the fact that interventionist and economic IGOs are capable of inducing all three convergence mechanisms provides a great challenge to the empirical analysis. We can still compare the magnitude of the converging effect of interventionist and economic IGOs to that of minimalist and economic IGOs: a significantly larger coefficient from interventionist and economic IGOs might suggest that in addition to policy learning and emulation that are both theoretically associated with interventionist and economic IGOs and minimalist and

\footnotetext{
${ }^{14}$ For example, European Central Bank promotes cultural days for their member states. We want to thank a reviewer for providing this great example.

${ }^{15}$ We thank one reviewer for suggesting this strategy to differentiate nested causal mechanisms. However, this "comparing magnitude of converging effects" approach is based on the "homogeneous-magnitude" assumption that we are going to discuss in the following paragraphs.
} 
economic IGOs, the coercion mechanism has additional converging effect through interventionist and economic IGOs.

However, this "comparing magnitude of converging effects" approach is based on the assumption that the converging effects of policy learning and emulation, if any, are homogeneous in magnitude per unit of IGO connection across different types of IGOs. In other words, the magnitude of the converging effect (from learning and from emulation) associated with one unit of IGO connection is constant across the three types of IGOs (minimalist and social-cultural IGOs $\left[I_{G O} O_{\text {Social,Minimalist }}\right]$, minimalist and economic IGOs $\left[I G O_{\text {Economic,Minimalist }}\right]$, and interventionist and economic IGOs $\left.\left[I G O_{\text {Economic,Interventionist }}\right]\right)$. If, for example, the magnitude of the "emulation-induced" converging effect per unit of minimalist and economic IGO is larger than that associated with one unit of minimalist and social-cultural IGO, a larger converging coefficient for minimalist and economic IGOs cannot be considered as an evidence that supports the additional effect of policy learning in minimalist and economic IGOs. The reason is that this larger converging coefficient might simply be a function of a stronger emulation effect per unit of IGO connection in minimalist and economic IGOs. Without this "homogeneous-magnitude" assumption, we can only test whether connections in minimalist and economic IGOs (IGOEconomic,Minimalist $)$ and interventionist and economic IGOs (IGOEconomic,Interventionist $)$ cause policy convergence without being able to specify particular causal mechanism(s) at work. ${ }^{16}$ The emulation mechanism, however, can be tested in the context of minimalist and social-cultural IGOs (IGO Social,Minimalist $)$ without holding this "homogeneous-magnitude" assumption.

In addition to the "comparing magnitude of converging effects" approach, for the three interventionist and economic IGOs that we focused on in this research (the GATT/WTO, the OECD, and the EEC/EU), we can look at whether there is a converging effect from these IGOs in the policy areas that they do not regulate directly. The rationale is that for policy areas that are not directly regulated by these strong IGOs, they can only affect policy by learning and/or emulation. For example, if the GATT/WTO has a converging effect on policies other than tariff and non-tariff barriers, we expect that it is not the GATT/WTO's coercive effect but rather learning and/or emulation that cause convergence. ${ }^{17}$

\section{Testing IGO Network Converging Effects}

Policy Distance in a Multidimensional Policy Space

Most studies on policy diffusion and convergence to date focus on changes in one specific policy. In this study, we provide an alternative way to capture convergence by bringing in more domestic policies. More specifically, to capture patterns of convergence, we conceptualize and construct a multi-dimensional space of domestic economic policies, with each dimension specifying one important domestic economic policy. In this way, we are able to locate every national economy in this policy space (given available data) and trace their movements over time. If convergence really happened, we are expected to see distances between countries to shrink. The policy distance between any two countries $i$ and $j$ in a multidimensional policy space is therefore a negative function of policy convergence, and we will use this dyadic policy distance as the dependent variable of the large- $n$ studies in the following sections.

\footnotetext{
${ }^{16}$ However, we have to admit that this is a very strong assumption. Future research should focus on how to differentiate convergence mechanisms without holding this assumption.

${ }^{17}$ We thank one reviewer for suggesting this strategy. However, it is hard in this large- $n$ study to further differentiate learning from emulation in the case of interventionist and economic IGOs after we establish the non-coercive converging effect of these IGOs.
} 
We provide a picture of convergence-divergence phenomena by including 11 domestic economic policies that can be broadly categorized into three important policy areas:

- size of government

- government consumption spending as a percentage of total consumption

- transfers and subsidies as a percentage of GDP

- government enterprises and investment as a percentage of total investment

- levels of top marginal tax rate

- access to sound money (monetary policies)

- money growth

- inflation variability

- inflation rate

- freedom to own foreign bank accounts

- regulation policies

- credit regulations

- labor regulations

- business regulations

The Fraser Economic Freedom of the World Index (Gartzke, Gwartney, and Lawson 2005) provides sufficient data for most of the economic entities in the world. We assume the equal importance of each policy dimension. Each of these 11 dimensions of domestic economic policies is standardized to a 0 to 10 scale to measure the extent to which domestic economic policies support personal choice, voluntary exchange, freedom to compete, and security of privately owned property. High values indicate low levels of government involvement in economic activities, such as retrenched government spending and transfers, low and stable inflation rates, and minimum regulations on labor, credit, and business- $\mathrm{a}$ policy configuration often considered as a neo-liberal model of economic management. ${ }^{18}$ We denote a country $i$ 's policy portfolio as $P^{i}=\left[p_{1}^{i} p_{2}^{i} \ldots p_{n}^{i}\right]^{\prime}$, with $n$ here as the number of policy dimensions concerned: $n=4$ for the policy space of the size of the government, $n=4$ for the policy space of the sound money, $n=3$ for that of the regulation policies, and finally $n=11$ for the overall policy space (that is, the aggregate of the three aforementioned policy spaces). The dependent variable(s) for the large- $n$ tests, that is, the policy distance between two countries, $d\left(P^{i}, P^{j}\right)$, then can be calculated accordingly in the $n$-dimensional policy spaces. We use Euclidean distance:

$$
d\left(P^{i}, P^{j}\right)=\sqrt{\sum_{n=1}^{N}\left(p_{n}^{i}-p_{n}^{j}\right)^{2}}
$$

where $p_{n}^{i}$ describes country $i$ 's score in the $n$th policy dimension. ${ }^{19}$

\footnotetext{
${ }^{18}$ See Appendix B for more detailed information on dimensions of policy areas.

19 The three policy areas and 11 policy dimensions that we choose do not cover all aspects of domestic economic policies. What we do here is to provide a multidimensional policy space approach into which people can always throw in more dimensions of domestic economic policies and have their own empirical view of the trends of policy convergence-divergence. Moreover, we have to acknowledge that the policy distance measure might overlook some details on specific practices and institutions during the information aggregation of the Fraser Index. For example, Central African Republic and Ghana both score " 7 " in regulations on credit in 2003. But these two countries differ substantially in subcomponents of credit regulations: the former scores high in interest rates regulations (a score of 9 on a 0-10 scale) but low in ownership of banks (5), while the latter scores high in ownership of banks (8) but low in interest rates regulations (4.9). Interest rates regulations and ownership of banks are two components of credit regulation policies.
} 
Table 3. Average and Standard Deviation (in parentheses) of Policy Distance

\begin{tabular}{lrrr}
\hline & 1990 & \multicolumn{1}{c}{1995} & \multicolumn{1}{c}{2000} \\
\hline Size of the government & $6.75(2.76)$ & $6.56(2.72)$ & $6.18(2.57)$ \\
Monetary policies & $8.97(4.92)$ & $7.99(5.37)$ & $6.59(4.42)$ \\
Regulation policies & $5.75(3.95)$ & $4.01(2.84)$ & $3.18(2.25)$ \\
Overall policy distance & $13.94(4.68)$ & $12.58(4.98)$ & $10.69(4.06)$ \\
\hline
\end{tabular}

Moreover, global level convergence-divergence in domestic economic policies can be estimated approximately by the average distance between national economies in the multi-dimensional policy space: the smaller the average distance, the higher the average level of convergence. At the same time, some measurement of the variation of policy distances, such as the standard deviation, provides information about possible clustering among countries. Low average distance with relatively high variation of distances reveal possible clustering of national economies in the multi-dimensional policy space. ${ }^{20}$ Table 3 indicates that both the average policy distances and the standard deviations of policy distances in the space of monetary policies and that of regulation policies have decreased significantly from 1990 to 2000. The drop in average distances and standard deviations in the space of the size of the government seems to be more incremental (from 6.75 to 6.18 and 2.76 to 2.57 respectively), revealing a much lower level of policy convergence in this policy area.

Another advantage of the multidimensional policy space approach has to do with the visualization of countries' policy changes. For instance, by using techniques of classical multidimensional scaling, we are able to collapse high dimensions of economic policies to lower dimensions and display countries' relative positions in the policy space. ${ }^{21}$ Because of page limits, we only display countries' movements in the overall policy space composed of all three policy areas (that is, all 11 dimensions) that are collapsed and represented in a two dimensional space in Figure 1.22 Here, one can notice the overall trend of convergence as countries move closer to the clustering of some wealthy OECD countries (circled) over time, and the fast movers include some Eastern European countries and some newly industrialized countries. Moreover, some clusters disappeared overtime, such as those of China (CHN), Russia (RUS), and Hungary (HUN) and those of Mexico (MEX), Ecuador (ECU), and Turkey (TUR) in 1990. The last row of Table 3 also clearly shows the overall pattern of convergence.

\footnotetext{
${ }^{20}$ However, there is one exceptional situation wherein the average policy distance measurement is unlikely to capture policy convergence defined by Berger and Dore (1996). This is when countries move closer to the role model of neo-liberal policy configurations, but they only move along one dimension therefore keeping their distance from each other constant. In this case, convergence does happen by Berger and Dore's definition, that is, countries move closer to the neo-liberal policy configuration, but policy distance remains constant. Policy distance thus fails to capture this convergence process. One can easily sense that this scenario might be a rare event, especially when there are multiple policy dimensions under consideration and these policy dimensions are likely to be correlated in real world politics (Cao, Prakash, and Ward 2007). Countries' movements in multidimensional policy spaces illustrated such as that in Figure 1 suggest that the convergence with constant policy distance scenario has not occurred between 1990 and 2000. This therefore supports using policy distance as a way to capture the convergence-divergence phenomena.

${ }^{21}$ The basic idea of multidimensional scaling is to decompose a distance/dissimilarity matrix of $n$ objects into $k$ vectors of coordinates to locate each object so that their distances in the $k$ dimensional space approximate those in the distance matrix. We use the policy distance matrix calculated from Equation 1 for multidimensional scaling. When doing multidimensional scaling, one needs to determine how many dimensions $(k)$ to choose: too many dimensions $(k>3)$ are impossible to display in a two-dimensional setting, while too few dimensions might lose important information carried by additional dimensions. One empirical rule is to choose a $k$ such that the sum of the first $k$ eigenvalues is of the order of 0.8 of the sum of the total eigenvalues (Everitt and Dunn 2001). We follow this criterion to pick the number of dimensions $k$ for plots in Figure 1.

${ }^{22}$ For more detailed descriptions of the convergence-divergence phenomenon as captured by countries' movements in multidimensional policy spaces, see Cao (2006).
} 


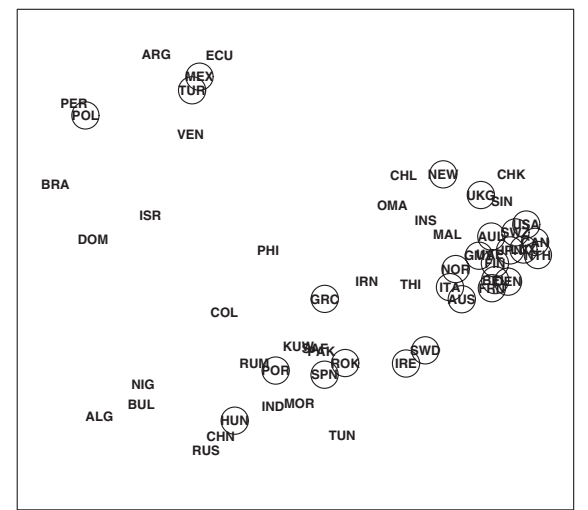

(A) 1990

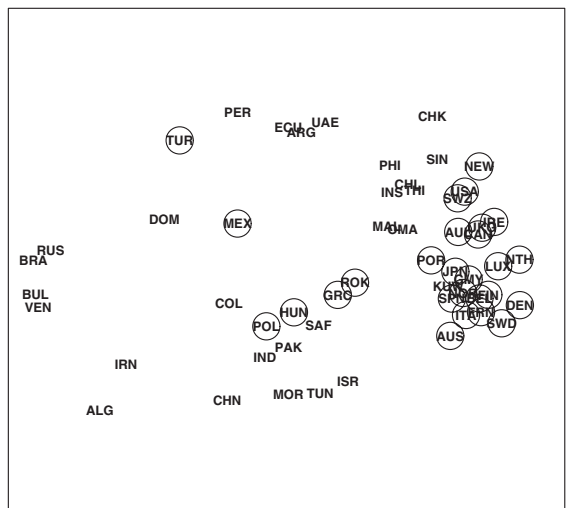

(B) 1995

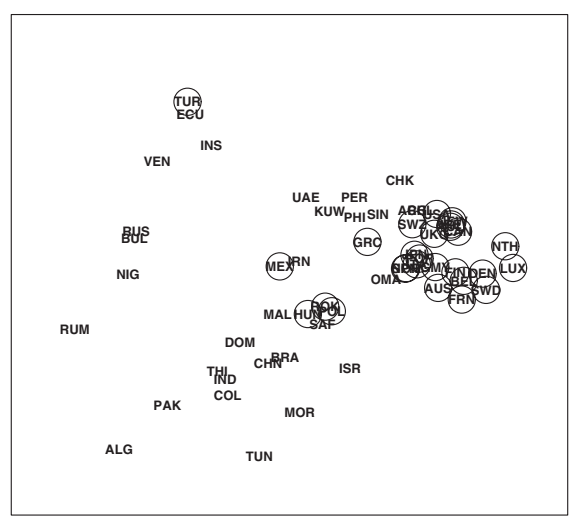

(C) 2000

FIG 1. Policy Distance in Overall Policy Space

Note. Countries' relative positions in a policy space characterizing domestic economic policies that can be categorized into three broad policy areas of domestic economic policies-the size of the government, monetary policies, and regulation policies. These 11 policy dimensions are collapsed into two dimensions by multi-dimensional scaling. The smaller the distance between two countries, the more similar their profiles on the 11 domestic economic policies selected. The plots show the movement of countries' positions in the abstract policy space from 1990 to 2000: group level convergence did happen as most countries moved to the OECD cluster (we circled the 30 OECD countries), but the extent of convergence varies across countries.

\section{Other Network Covariates to Model Policy Convergence}

In addition to the dynamics in the IGO networks, other important networks in international markets might have converging effects on domestic policy convergence. In this paper, we consider connections in trade networks, ties of common language, and proximity in geography. For the IGO networks, we have been concentrating on the mechanisms of coercion, learning, and emulation. The last two mechanisms can be considered as two related aspects of a socialization process in which higher levels of interactions between two countries facilitate policy learning and emulation and therefore cause policy diffusion and convergence. Similarly, high levels of bilateral trade between countries might also cause policy convergence. Therefore, we add in the variable trade, measured as the sheer volume of bilateral trade between two countries, to capture the socialization process in the network of trade.

Besides coercion, learning, and emulation, competition might also cause convergence. Competition refers to interdependence stemming from peer pressures 
between countries competing with each other, for example, for the same export markets and the same sources of finance (Burt 1992; Simmons and Elkins 2004; Simmons et al. 2006). Indeed, when competing in the international market, countries targeting the same sources of foreign investment and the same overseas markets are facing a collective action problem as they all want to be competitive, actually more competitive than their major competitors. A country thus adopts efficiency-mandated economic policies and institutions to gain advantages over its competitors. Other countries respond by going even further in that direction. Such competition at the group level results in convergence to liberal-style minimalism, or a "race to the bottom," among a group of competitors.

To capture the extent of competition among countries that target the same export markets, we calculated pair-wise structural equivalence based on sectorlevel bilateral data. We choose the categorization of United Nations' Standard International Trade Classification (SITC), Revision 2, to differentiate sectors of trade (UN 1975). This standard classifies 1,832 types of commodities traded in international markets into 10 sections, 63 divisions, 233 groups, and finally 786 subgroups. We followed the classification at section level to categorize 10 broad trade sectors in international commerce:

- Food and live animals directly for food

- Beverages and tobacco

- Crude materials, inedible, except fuels

- Mineral fuels, lubricants and related materials

- Animal and vegetable oils, fats and waxes

- Chemical and related products

- Manufactured goods, classified chiefly by material

- Machinery and transport equipment

- Miscellaneous manufactured articles

- Commodities and transactions not classified elsewhere

Data for dyadic sector-level trade are from the Center of International Data at University of California, Davis (Feenstra, Lipsey, Deng, Ma, and Mo 2005). This data set covers international commerce at the dyadic level from 1962 to 2000 and details bilateral trade across different commodities at the level of four-digits Standard International Trade Classification (SITC). Aggregating bilateral trade to one-digit level gives rise to the 10 sectors we just described. A correlation matrix of a country's export profile across different trade sectors is then generated to capture this structural similarity (Snyder and Kick 1979; Nemeth and Smith 1985; Smith and White 1992). Calculating the first correlation between country $i$ 's and $j$ 's export profiles (that is, the correlation between their bilateral exports across 10 sectors), we constructed a correlation measure capturing the structural equivalence between any two countries $i$ and $j$, StrucEquivexp, in the network of global trade. The value of the correlation is bounded between -1 and 1 , with 1 representing completely structurally equivalent positions between two countries, that is, exact profiles of bilateral exports across 10 sectors of trade. On the other hand, -1 captures the situation where two countries share the most dissimilar export profiles.

We also control for the effects of distance in geography (Distance) and ties of common language (Com. Lang.) on policy convergence. ${ }^{23}$ Finally, there is an alternative hypothesis that policy convergence appears because of a liberalization trend which might be a function of some cultural norms that operate without

\footnotetext{
${ }^{23}$ We calculate distance using the Haversine formula with data on latitude and longitude of capital cities taken from the world.cities database maintained as part of the maps package in the $\mathcal{R}$ statistical programming package. Distance was calculated in thousands of kilometers. Com. Lang. is a binary variable with 1 representing two countries sharing a common official language. Data on countries' primary language(s) are from the CIA Factbook (CIA 2004).
} 
reference to specific network mechanisms. We therefore include period fixed effects to control for a potential liberalization trend. ${ }^{24}$

\section{Modeling the Overall Policy Distance}

We relied on a time-series-cross-sectional data with a $T$ (time) equal to 3: 1990, 1995,2000 , and a $N$ (countries) equal to 55 to model the policy distance, between any two countries $i$ and $j$ in a policy space, as a function of IGO network variables (shared membership in the EU, shared membership in the WTO, shared membership in the OECD, the number of shared memberships in minimalist IGOs with economic functions, and the number of shared memberships in minimalist IGOs with social and cultural functions), the volume of shared bilateral trade, the level of structural equivalence in exports, existence/absense of common language ties, and proximity in geography. ${ }^{25}$ I chose a simple OLS regression with lagged dependent variable (lagged by 5 years) and year fixed effects to incorporate the time dimension. ${ }^{26}$ The basic model to estimate is as follows:

$$
Y_{i, j, t}=\beta_{0}+X_{i, j, t} \beta_{x}+Y_{i, j, t-5} \beta_{t-5}+\beta_{t} \text { Year }_{t}+\varepsilon_{i, j, t}
$$

where $Y_{i, j, t}$ is policy distance between $i$ and $j$ at year $t, X_{i, j, t}$ including dyadic covariates-different IGO networks (including IGO Social,Minimalist, IGOEconomic,Minimalist, $E E C / E U, G A T T / W T O$, and $O E C D)$, structural equivalence in exports, bilateral trade, distance, and common language. ${ }^{27} Y_{i, j, t-5}$ is the time lag, Year $_{t}$ the year fixed effect (to control for a potential liberalization trend), and $\varepsilon_{i, j, t}$ random error. $^{28}$

${ }^{24}$ Period/year fixed effects are included in all the model specifications (including the causal modeling part of the analysis) to control for time trend and are reported in Tables 6 and 5. Year fixed effect Year 2000 (the reference year is 1995) has a significant and negative effect on policy distance across most of the model specifications, therefore revealing a liberalization trend.

${ }^{25}$ The countries included in this study are Algeria, Argentina, Australia, Austria, Belgium, Brazil, Bulgaria, Canada, Chile, China, Colombia, Denmark, Dominican Republic, Ecuador, Finland, France, Germany, Greece, Hungary, India, Indonesia, Iran, Ireland, Israel, Italy, Japan, Korean Republic, Kuwait, Malaysia, Mexico, Morocco, Netherlands, New Zealand, Nigeria, Norway, Oman, Pakistan, Peru, Philippines, Poland, Portugal, Romania, Russian Federation, Singapore, South Africa, Spain, Sweden, Switzerland, Thailand, Tunisia, Turkey, United Arab Emirates, United Kingdom, United States, and Venezuela.

${ }^{26}$ The data from the Fraser Index for our dependent variable are only available for every 5 years until 2000 (... $1990,1995,2000, \ldots)$.

${ }^{27}$ Unobserved variables are a potential threat to the analysis. It is a common practice to control for potential unobserved variables by fixed effects. Fixed effects are often useful as they exploit the existence of multiple observations on cross-sectional units over time to account for unobserved, unit-specific heterogeneity while obtaining estimates on variables of substantive interest. However, the use of fixed effects also has its drawbacks. First, the inclusion of a lagged dependent variable can cause bias and inconsistency in the parameter estimates in fixed effect models (Beck and Katz 1995). Second, fixed effect models lack the ability to make inferences about time invariant or slow-moving variables because those variables are either perfectly or highly collinear with fixed effects and their coefficients are either not identified or difficult to estimate with precision (but see Plümper and Troeger 2007). In our empirical analysis, lagged dependent variable is included because policy positions today are likely a positive function of policy positions of the past; some explanatory variables are time invariant such as geographical distance and common language; others are slow-moving variables such as shared EEC/EU membership. Some of the results from fixed effects model show signs of biased estimates caused by collinearity. For example, the lagged dependent variable has a significant and "negative" sign which indicates a rather unlikely scenario: the policy position today is a negative function of that of the past. We face a trade-off between accounting for potential unit heterogeneity and reaching substantive conclusions about theoretically important variables. Because including fixed effects already shows signs of biased estimates, we choose not to include fixed effects in order to get better estimates of theoretically important variables.

${ }^{28}$ An alternative strategy to year fixed effects is to calculate the average policy distance between all dyads in a given year and use it as a control variable. This is equivalent to adding a year fixed effect: the average policy distance for a given year is constant for all dyads. Data analysis shows that the results from models using average policy distance are the same as those from models using year fixed effects. We do not report the regression tables for models with average policy distance, but they are available from the author upon request. We want to thank one reviewer for suggesting this alternative average policy distance strategy. 
Table 5 summarizes the findings of relationships between IGOs and overall policy distance. Again, IGOSocial,Minimalist are the shared number of IGOs with minimalist capacity and social/cultural functions between country $i$ and $j$, and $I G O_{E c o n o m i c, \text { Minimalist }}$ are the shared number of IGOs with minimalist capacity and economic functions. EEC/EU, GATT/WTO, and $O E C D$ are binary variables for shared membership in each of these IGOs respectively. From the basic correlation statistics in Table 4, we can see that IGO networks covariates are correlated at a relatively high level. For instance, IGO Social,Minimalist and $I G O_{E c o n o m i c, M i n i m a l i s t}$ are correlated at the level of 0.73 , while $E E C / E U$ is correlated to IGO Social,Minimalist at 0.67 . Therefore, in addition to a full model, we test three more model specifications with each involving only one type of IGOs.

The results from Table 5 reveal that $I G O_{\text {Social,Minimalist }}$ does not have clear and consistent effects on overall policy distance as we can see from the different estimates from the full model and the second model specifications. Recall that minimalist and social-cultural IGOs (IGO Social,Minimalist $)$ induce policy convergence only through the mechanism of policy emulation (Table 2). This therefore casts doubts on the policy emulation mechanism proposed in previous sections. Moreover, notice that common language (Com Lang) also has no consistent effects on policy distance and these two variables are not correlated at any significant level (the correlation is at 0.13 , see Table 4 ). This further suggests that the hypothesis that policy emulation based on affinity or a sense of community and common cultural heritage causes policy convergence does not hold, at least for overall policy distance.

$I G O_{\text {Economic,Minimalist, }}$ on the other hand, has consistent and negative effects on overall policy distance. The higher the shared number of minimalist IGOs with economic functions, the more similar the two countries are in their domestic economic policy configurations. Notice that minimalist and economic IGOs might induce policy convergence through both learning and emulation (see Table 2). However, we already know that $I G O_{\text {Social,Minimalist }}$ has no converging effect on policy. Therefore, the magnitude of the "emulation-induced" converging effect is essentially 0 for minimalist IGOs with social-cultural functions. If we allow the "homogeneous-magnitude" assumption, that is, the magnitude of the "emulation-induced" converging effect associated with one unit of IGO connection is constant across minimalist IGOs regardless of IGO functions (economic vs. social-cultural), we know that the "emulationinduced" converging effect is also likely to be 0 for minimalist IGOs with economic functions. Therefore, the converging effect induced by minimalist IGOs with economic functions as shown in Table 5 must be a function of policy learning since the effect of policy emulation is expected to be 0 .

The three interventionist and economic IGOs, that is, the EEC/EU, the GATT/WTO, and the OECD, all have an important negative (and therefore converging) effect on overall policy distance (Table 5). This finding itself cannot tell us the exact mechanism(s) that cause(s) policy convergence because in addition to coercion, interventionist IGOs are also capable of inducing learning and emulation. However, the absolute magnitude of the converging effects for the EEC/EU, the GATT/WTO, and the OECD (1.98, 0.50, and 1.67 in the full model, respectively) are much larger than that of minimalist and economic IGOs (0.08 in the full model) which could cause convergence through learning and emulation but not coercion. We suspect that these large and additional converging effects are the result of coercion from these interventionist IGOs. This suggests that the EEC/EU, the GATT/WTO, and the OECD have "coercion-induced" converging effects on overall policy configurations of their member states. Again, we assume that the magnitude of the learning and/or 


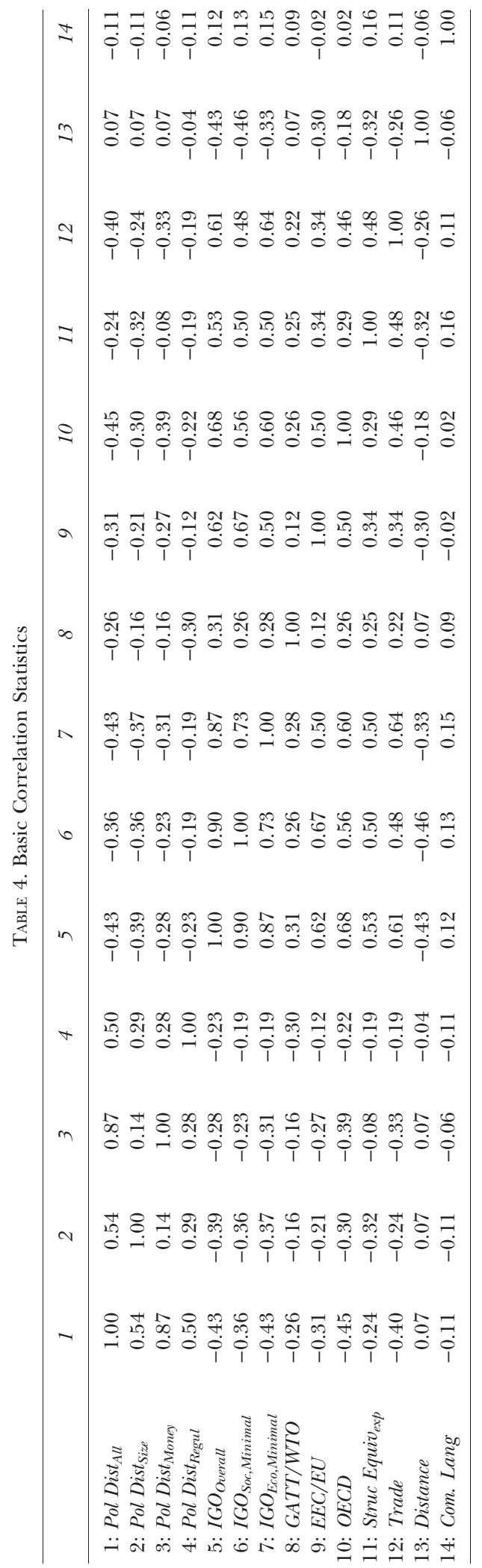




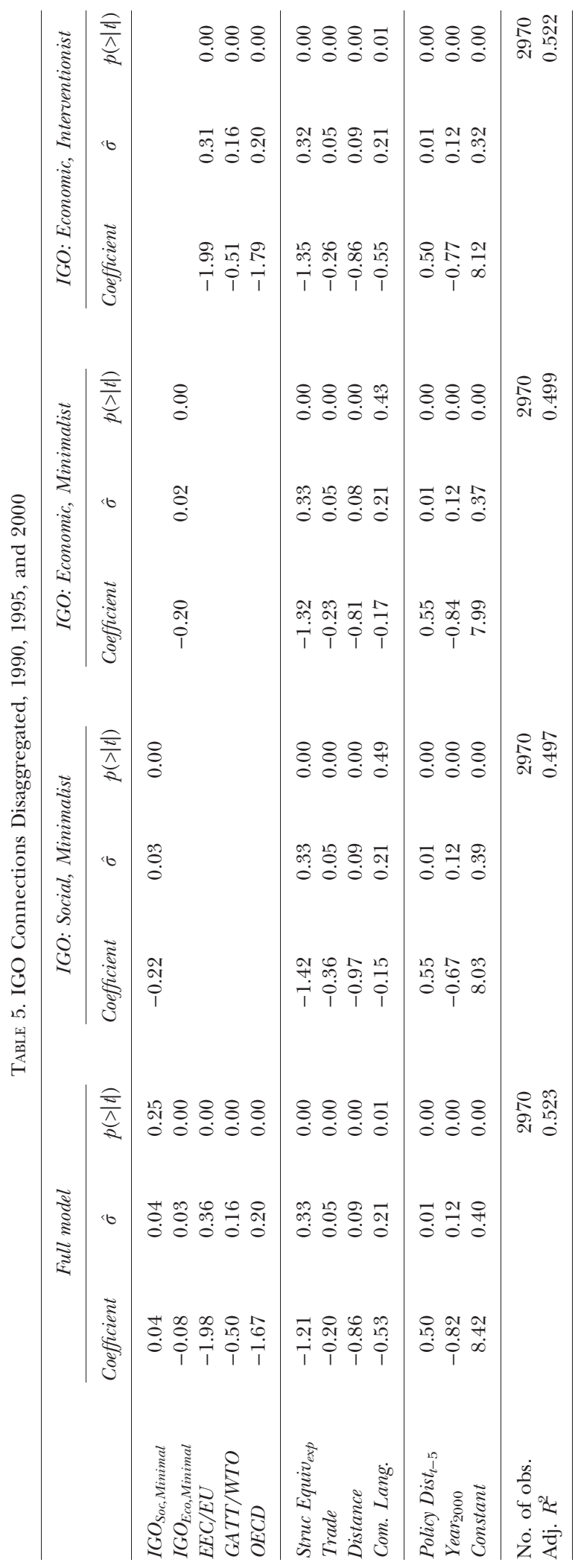


emulation-induced converging effect associated with one unit of IGO connection is constant across minimalist and economic IGOs and interventionist and economic IGOs. ${ }^{29}$ In order to determine whether the EEC/EU, the GATT/WTO, and the OECD also socialize their member states by promoting policy learning and/or emulation, we need to disaggregate the overall policy space to see whether there is converging effect from these IGOs on the policy areas that they do not regulate directly. ${ }^{30}$

\section{Disaggregating the Overall Policy Distance}

Recall that the overall policy distance is calculated by taking into account 11 dimensions of domestic economic policies that can be categorized as those related to the size of the government, monetary policies, and regulations. However, different IGO networks might affect different policy areas differently. We therefore disaggregated the overall policy distance into policy distances in the aforementioned three policy areas and used each of them as the response variable for the same regression model in Equation 2. Table 6 and Figure 2 report the findings: the former provides detailed numbers and the latter summarizes these numbers and provides visuals of $95 \%$ confidence intervals of coefficient estimates for the network covariates. Figure $2 b$ is of great interest to us as it reveals whether there is converging effect of interventionist and economic IGOs on the policy areas that they do not regulate directly, and therefore whether they also socialize states by facilitating policy learning and/or emulation. However, as both the EEC/EU and the OECD have broad institutional agendas and might regulate policies in all three policy areas, we cannot determine whether they facilitate policy learning and emulation. The GATT/WTO, on the other hand, does not regulate (at least directly) policies in any of the three policy areas. A careful reading of

\footnotetext{
${ }^{29}$ In this large- $n$ studies, we are first of all interested in the average converging effect by coercion, learning, and emulation through IGO networks. However, we have to acknowledge that it is likely that IGO networks have different levels of converging effects for different countries. For instance, interventionist IGOs such as the EU are more effective in coercing some states but not others. We thank one reviewer for raising this important question as it points to one direction for future research. The interesting question is what are the country level characteristics that determine how easily one country would be coerced by strong IGOs. However, because the unit of analysis of this paper is at the dyadic level, it is hard to incorporate country level variables. Future research with models similar to Henisz, Zelner, and Guillén's (2005) could better answer this question.

${ }^{30}$ The IMF is a champion of the literature on IGO coercion. One reviewer suggested that instead of using formal membership, other indicators such as the size of the loans taken from the IMF are better to capture the coercion effect of strong IGOs (Henisz, Zelner, and Guillén 2005; Polillo and Guillén 2005). We follow this suggestion and use the data on countries' use of IMF credit to measure to the extent to which countries are subject to the coercive power of the IMF. One empirical strategy to define IMF lending at the country-pair level is to use the lower value of IMF credit among the two countries in country-pair $\{i, j\}$. The rationale is that we are able to observe decreasing policy distance between two countries when both countries are subject to certain level of IMF lending and coercive power, and they both make policy changes and move to the same direction in the policy space. Data analysis indicates that IMF lending does not cause policy convergence. However, we are uncertain that this can serve as strong evidence against IMF's coercive effect because the strategy to define IMF Lending as the lower value of IMF credit among two countries is not unproblematic. For example, assuming country $i$ is subject to IMF's coercive power and changes its policies to become more neo-liberal, this might reduce the policy distance between county $i$ and country $j$ even if $j$ does not use IMF lending as long as $j$ is already "neo-liberal" (that is, $i$ is moving toward $j$ ). But because we use the lower value of IMF credit among $i$ and $j$, the IMF Lending variable will take the value of 0 , which numerically means the absence of IMF's coercive effect. The dyadic nature of the dependent variable makes the operationalization of the IMF Lending variable difficult. Therefore, the finding that the IMF does not have coercive effect on policy convergence is not conclusive and we do not report the findings in the main text (regression tables are available from the author upon request). We have to move from dyadic analysis to monadic/country level analysis to test further the coercive power of the IMF in future research.
} 
Table 6. IGO Effects on Policy Distance Disaggregated, 1990, 1995, and 2000

\begin{tabular}{|c|c|c|c|c|c|c|c|c|c|}
\hline & \multicolumn{3}{|c|}{ Size of government } & \multicolumn{3}{|c|}{ Monetary policies } & \multicolumn{3}{|c|}{ Regulatory policies } \\
\hline & Coefficient & $\hat{\sigma}$ & $p(>|t|)$ & Coefficient & $\hat{\sigma}$ & $p(>|t|)$ & Coefficient & $\hat{\sigma}$ & $p(>|t|)$ \\
\hline$I G O_{\text {Soc,Mini }}$ & 0.03 & 0.02 & 0.12 & 0.14 & 0.05 & 0.00 & 0.01 & 0.02 & 0.85 \\
\hline$I G O_{E c o, M i n i}$ & -0.05 & 0.01 & 0.00 & -0.06 & 0.03 & 0.09 & 0.02 & 0.02 & 0.24 \\
\hline$E E C / E U$ & 0.04 & 0.18 & 0.82 & -3.65 & 0.44 & 0.00 & 0.05 & 0.22 & 0.83 \\
\hline GATT/WTO & 0.16 & 0.08 & 0.05 & -0.44 & 0.19 & 0.02 & -0.79 & 0.09 & 0.00 \\
\hline$O E C D$ & -0.48 & 0.10 & 0.00 & -2.32 & 0.24 & 0.00 & -0.21 & 0.12 & 0.08 \\
\hline Struc Equiv $_{\text {exp }}$ & -0.79 & 0.17 & 0.00 & 0.85 & 0.40 & 0.03 & -1.03 & 0.19 & 0.00 \\
\hline Trade & 0.08 & 0.03 & 0.00 & -0.40 & 0.06 & 0.00 & 0.02 & 0.03 & 0.48 \\
\hline Distance & -0.06 & 0.05 & 0.20 & -0.79 & 0.11 & 0.00 & -0.12 & 0.05 & 0.03 \\
\hline Com. Lang. & -0.06 & 0.11 & 0.57 & -0.68 & 0.25 & 0.01 & -0.18 & 0.12 & 0.17 \\
\hline${\text { Policy } \text { Dist }_{t-5}}$ & 0.72 & 0.01 & 0.00 & 0.43 & 0.02 & 0.00 & 0.48 & 0.01 & 0.00 \\
\hline Year $_{2000}$ & -0.15 & 0.06 & 0.02 & -0.72 & 0.15 & 0.00 & -0.10 & 0.07 & 0.17 \\
\hline Constant & 2.23 & 0.21 & 0.00 & 5.63 & 0.41 & 0.00 & 2.47 & 0.21 & 0.00 \\
\hline No. of obs. & & & 2970 & & & 2970 & & & 2966 \\
\hline Adj. $R^{2}$ & & & 0.616 & & & 0.418 & & & 0.470 \\
\hline
\end{tabular}

Figure $2 \mathrm{~b}$ reveals that GATT/WTO's converging effect is evident in monetary and regulatory policies. This suggests that at least in the case of the GATT/WTO, interventionist and economic IGOs also socialize states by facilitating policy learning and/or emulation.

Another advantage of disaggregating the overall policy distance is to answer the question whether and how different IGO networks affect different policy areas differently. Figure $2 \mathrm{~b}$ indicates that common EEC/EU membership is only negatively associated with policy distance in monetary policies, and it has no clear association with those in policies related to government spending and taxation and regulations. GATT/WTO's converging effect is only evident in monetary and regulatory policies. Again, policies related to the ways government collects and spends money (the size of the government) are quite resilient to the influence of important IGOs. One surprising finding is the effect of OECD memberships. Here, we find significant negative effects of OECD memberships on all of the three policy areas (though the negative association with regulation policies is much lower). The OECD is classified as an intergovernmental organization with general economic functions and interventionist institutional capacity to implement policies. However, we know much less about its role in affecting its member states' domestic policies as much fewer studies have focused on the OECD than on the WTO and the EU. We know that OECD might have capacity to change its member states' behavior in the area of monetary policies. For instance, OECD's Code of Liberalization of Capital Movements is non-negotiable for its members and its commitments are taken quite seriously (Abdelal 2006). However, for other policy areas, especially government spending and taxation, we know very little so far.

Finally, Figure $2 \mathrm{a}$ reveals that $I G O_{\text {Social,Minimalist }}$ has no converging effect on domestic economic policies: its associations with the size of the government and regulatory policies are not determined and it has a diverging effect on monetary policies. The converging effects of $I G O_{\text {Economic,Minimalist }}$ are most evident for policies concerning the size of government. For monetary policies, it has a negative effect, but the confidence level is much lower (with a $p$-value of 0.09 , see Table 6 ). For regulatory policies, there is no determinable association. Therefore, if economic minimalist IGOs ever have converging effects on domestic economic policies, they are more likely to 

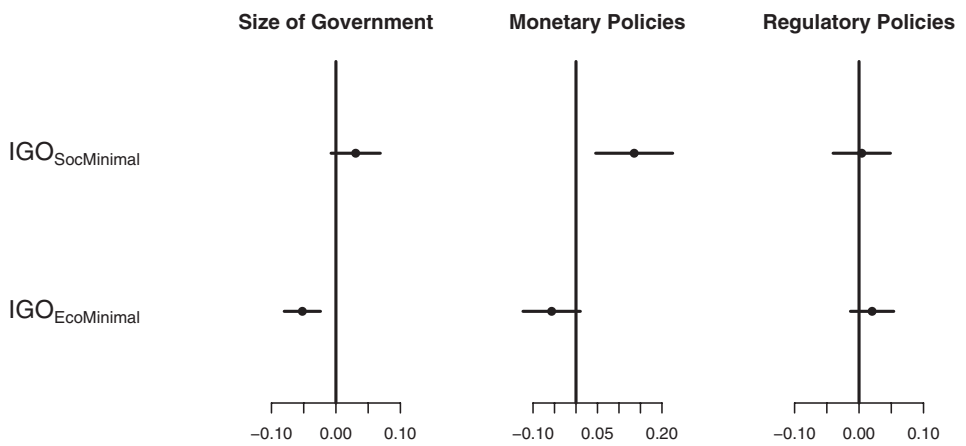

(A) Minimalist IGOs: Emulation and Learning
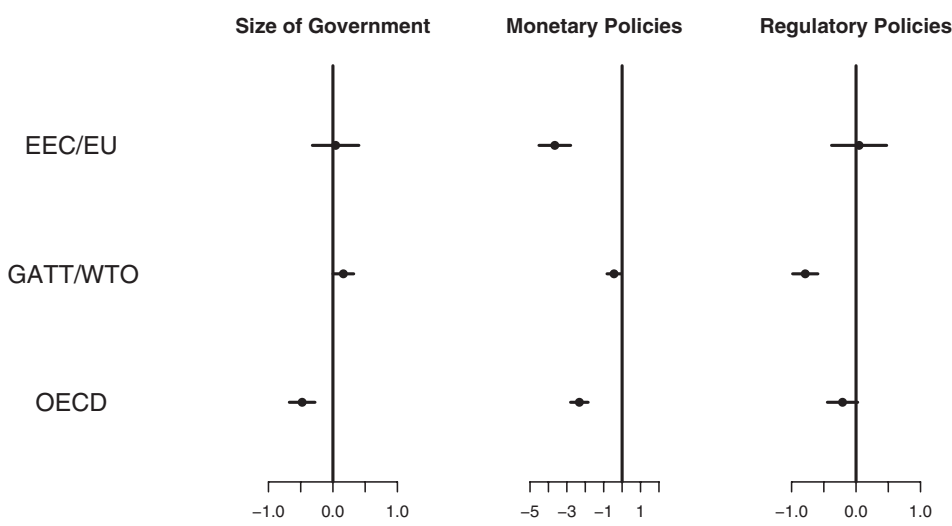

(B) Interventionist IGOs: Emulation, Learning, and Coercion

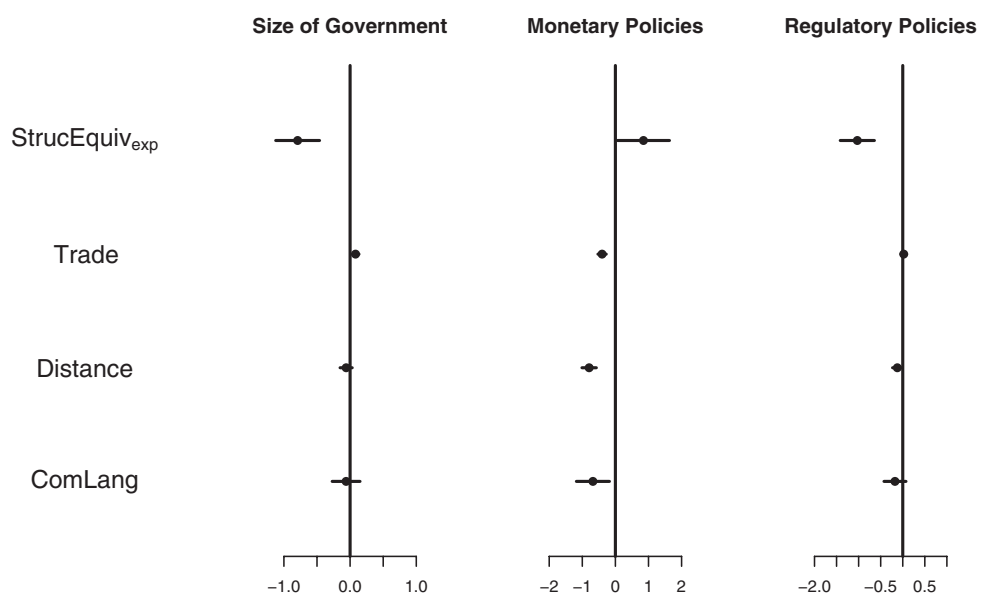

(C) Other Network Covariates

Fig 2. 95\% Confidence Intervals of the Coefficients of IGO Network Covariates 
affect policies related to government spending and taxation, and monetary policies. ${ }^{31}$

\section{Endogeneity Problem and Causal Modeling}

So far, we have been testing statistical associations between IGO networks and policy distance. However, not unlike many studies in social sciences, we make claims about causal relations from time to time. Statements such as "negative effect" and "diverging effect" often imply a causal relationship. However, to say that characteristics of IGO networks are statistically associated with convergencedivergence of domestic economic policies is different from the claim that the former causes the latter.

One way to define causality or causal effects follows the logic of counterfactuals and tries to approximate, for studies based on observational data, randomized experiments where treatment and control groups are randomly selected. In the story of IGO networks and domestic policy convergence, let us choose $T$ as the treatment variable where $T=1$ denotes a shared IGO membership of GATT/ WTO, and $T=0$ the absence of a common membership in this IGO. The response variable is still policy distance. $Y_{T=1}$ is the policy distance we observe between two countries if this dyad receives the treatment (common membership of GATT/WTO) and $Y_{T=0}$ otherwise. Causal effects are comparisons of $Y_{T=1}$ and $Y_{T=0}$, often the difference between the two: $Y_{T=1}-Y_{T=0}$ (Rubin 1974; Rosenbaum and Rubin 1983).

However, in reality, one can only observe either $Y_{T=1}$ or $Y_{T=0}$ : two countries, at one time point, can only either share or not share a common GATT/WTO membership. One can then turn to estimate the average treatment effect, that is, $E(Y \mid T=1)-E(Y \mid T=0)$ : on average, the difference between the expected policy distance of a dyad of countries both belonging to GATT/WTO and a dyad not sharing common GATT/WTO membership. The estimation of the average treatment effect can be achieved in randomized experiments where units are randomly assigned to treatment and control groups, therefore the pretreatment characteristics/covariates of treatment group units and control units, $X$, are similar enough that the only difference between the two groups is the treatment itself. The problem is that, for studies based on observational data, randomization is impossible: no one has the power to randomly assign GATT/ WTO membership to countries. It is more likely, however, that countries belonging to the same IGO are different from those non-member states: pretreatment characteristics, $X$, might determine which countries receive treatment $(T=1)$ and which countries do not $(T=0)$. In other words, the key causal variable (the treatment), co-membership in GATT/WTO for instance, is itself endogenous. This endogeneity problem of intergovernmental organizations

\footnotetext{
${ }^{31}$ For monetary policies, economic theory suggests that a fixed exchange rate regime under full capital mobility causes convergence; countries lose monetary autonomy under these two conditions. To control for this potential omitted variable in the case of monetary policy convergence, we create a binary variable Fixedmobile which equals 1 if both countries in a dyad have fixed exchange rate regime and are under full capital mobility; Fixedmobile equals 0 otherwise. We use a recent data source on exchange rates from Shambaugh (2004) and we use the Chinn-Ito Financial Openness variable as a proxy for capital mobility (Chinn and Ito 2006). The findings indicate that the effect of fixed exchange rate regime and full capital mobility on monetary policy convergence is important. The magnitude of this effect is close to that of the "net" effect of the EEC/EU (after controlling Fixedmobile) and that of the OECD. However, the estimated effects of other variables change very little, in terms of both estimated mean coefficients and standard errors. For example, after controlling for fixed exchange rate regime and full capital mobility, the estimated mean coefficient of the EEC/EU changes from -3.65 to -3.29 , both with a $p$-value smaller than 0.00 . This means that the new variable Fixedmobile only picks up information from the residuals of the second model specification (on monetary policies) in Table 6. We want to thank a reviewer for his/her suggestion to control for this potential omitted variable. Because of page limits, we have chosen not to report regression tables, but they are available from the author upon request.
} 
(and international institutions in general) casts doubt on any causal claim that we want to infer beyond simply noting the statistical associations between IGO networks and domestic policy outcomes. One can easily point out alternative hypotheses: high levels of economic interactions between countries (trade and FDI for instance) cause policy convergence and higher levels of shared IGO memberships at the same time, therefore even though there is no real effect of IGO networks on policy outcomes, we find statistical association between them.

To differentiate statistical association from causal effect, we need to use a causal model. One way is to approximate randomized experiments through matching. The basic idea is to select a subset of the observational data wherein the treatment units and control units are matched so that they have the same characteristics, that is, the same distributions for pretreatment covariates $X$. In this way, the link between pretreatment covariates $X$ and treatment assignment $T$ might be broken (approximately) in a way that brings us much closer to the ideal situation where the treatment and control units had been assigned randomly from a single population. Imai and van Dyk (2004) have developed the broad notion of using propensity scores as a means of managing sample matching in parametric studies, Ho, Imai, King, and Stuart (2004) have developed the MatchIt $R$ library that implements these procedures to produce matched subsamples. Once the matched subsamples are produced, one can simply calculate the average treatment effect $(E(Y \mid T=1)-E(Y \mid T=0))$; one can also proceed with normal parametric model fitting as we will do in the following analysis.

We follow Ho et al. (2004) and use MatchIt to find subsamples of the data where the assignment of treatments is not correlated with pretreatment covariates $X$. We consider each treatment respectively. We choose one from five following IGO network treatments-IGO Social,Minimalist, IGO Economic,Minimalist, EEC/EU, $G A T T / W T O$, and $O E C D$, then find subsamples based on matching on the other four IGO network treatments and pretreatment covariates $X$ including structural equivalence in exports, trade, distance, common language, and policy distance at year $t-5$ (the lagged response variable). For example, when we consider common GATT/WTO membership as the treatment, we match on

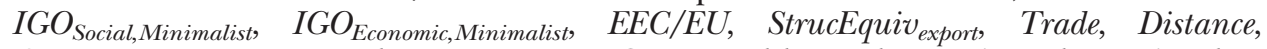
Common Language, and PolicyDist $t_{t-5}$. One problem that arises here is that unlike the EEC/EU, GATT/WTO and OECD variables, the IGO Social,Minimalist and $I G O_{\text {Economic,Minimalist }}$ are not binary variables. We need to truncate these two variables in order to draw a clear line between treatment and control groups. The question then becomes what is an appropriate threshold, and there is really no prior theoretical knowledge to tell where the critical point is for the cumulative effects of IGO memberships.

We turn to a very rudimentary way to look for and test possible thresholds. Figure 3 plots shared IGO memberships ( $x$-axis) against overall policy distance: the first plot for minimalist IGOs with social and cultural functions and the second minimalist IGOs with economic functions. Notice that we also draw a Loess non-parametric line for each plot to trace the trend of local correlation between IGO memberships and policy distance. Overall, these two plots not only reveal a linear relationship (which happens to be one key assumption of the OLS model we use), but they also show us that the negative associations are less evident at the lower end of IGO memberships, especially for Figure 3a. The turning point (to a more evident negative relationship) seems to lie somewhere between 6 and 7 shared IGO memberships. Moreover, the mean shared minimalist IGOs with social and cultural functions is 6.1 and that of minimalist IGOs with economic functions is 6.6. We therefore decided to use 7 as the threshold to dichotomize these two variables: values higher than or equal to 7 were coded 


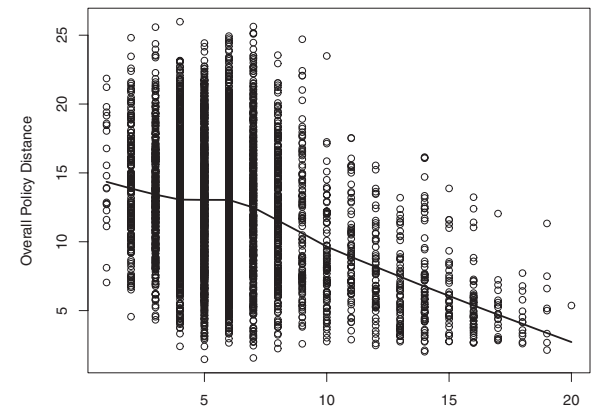

(A) IGO connections: social and minimalist

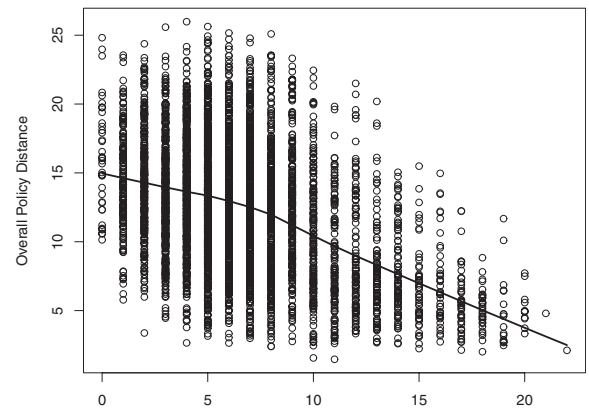

(B) IGO connections: economic and minimalist

FIG 3. Shared Minimalist IGOs and Policy Distance

as 1 , that is, receiving a treatment; whereas values lower than 7 were coded as 0 -assigned to control group. ${ }^{32}$

Finally, reverse causality is another serious threat to any causal claim made in this paper. A legitimate question is what if countries with similar domestic politics and priorities are more likely to join the same IGOs? Matching itself cannot solve the reverse causality problem. An instrumental variable approach, on the other hand, is probably a promising way to solve this problem. The basic idea of this approach is to find some instruments, that is, variables that are closely correlated with IGO network variables but not correlated with policy distance variables, use these instruments as predictors of IGO network variables, then replace the real values of IGO network variables with their predicted values in regression analysis. The goal was to tease out, if any, the part of the IGO network variables that are potentially caused by policy similarities. The key, and also the difficulty for this research, was to find appropriate instruments since the covariates that we considered so far can easily be both correlated with IGO network variables and policy distances (see Table 4). We therefore postponed carrying out an instrumental variable approach until later research. Instead, we chose to use a time lag of five years for both treatment variable $T$ and pretreatment covariates $X$ (both in matching procedures and in the final parametric model fitting), hoping that five years' lag is long enough to weaken the effect of reverse causality. Therefore, we estimated, after matching ${ }^{33}$, the following model:

$$
Y_{i, j, t}=\beta_{0}+\beta_{T} T_{i, j, t-5}+X_{i, j, t-5} \beta_{x}+\beta_{t-5} Y_{i, j, t-5}+\beta_{t} \text { Year }_{t}+\varepsilon_{i, j, t}
$$

where $\beta_{T}$ is the causal effect of relevant IGO network variable that we are interested in. ${ }^{34}$

We did matching for the five IGO network variables respectively, and for each we considered their causal effects on the overall policy distance, and disaggregated policy distances in policy areas of (1) the size of the government, (2) monetary policies, and (3) regulatory policies. Figure 4 summarizes the causal effects, $\beta_{T}$. Compared to Figure 2, the findings for IGO networks on overall policy distance confirm what we found in previous sections: $I G O_{E c o n o m i c, \text { Minimalist }} E E C / E U$,

\footnotetext{
${ }^{32}$ We also try other thresholds such as 5, 6, and 10, and they give similar levels of support for our findings in Figure 4 in terms of the causal effects of $I G O_{\text {Social,Minimalist }}$ and IGO Economic,Minimalist on policy distances.

${ }^{33}$ We use the nearest neighborhood matching and check the balance after matching. Matching significantly improves balance.

${ }^{34}$ We estimate year fixed effects, $\beta_{t}$ Year $_{t}$, to control for the alternative hypothesis that convergence occurs because of a liberalization trend.
} 


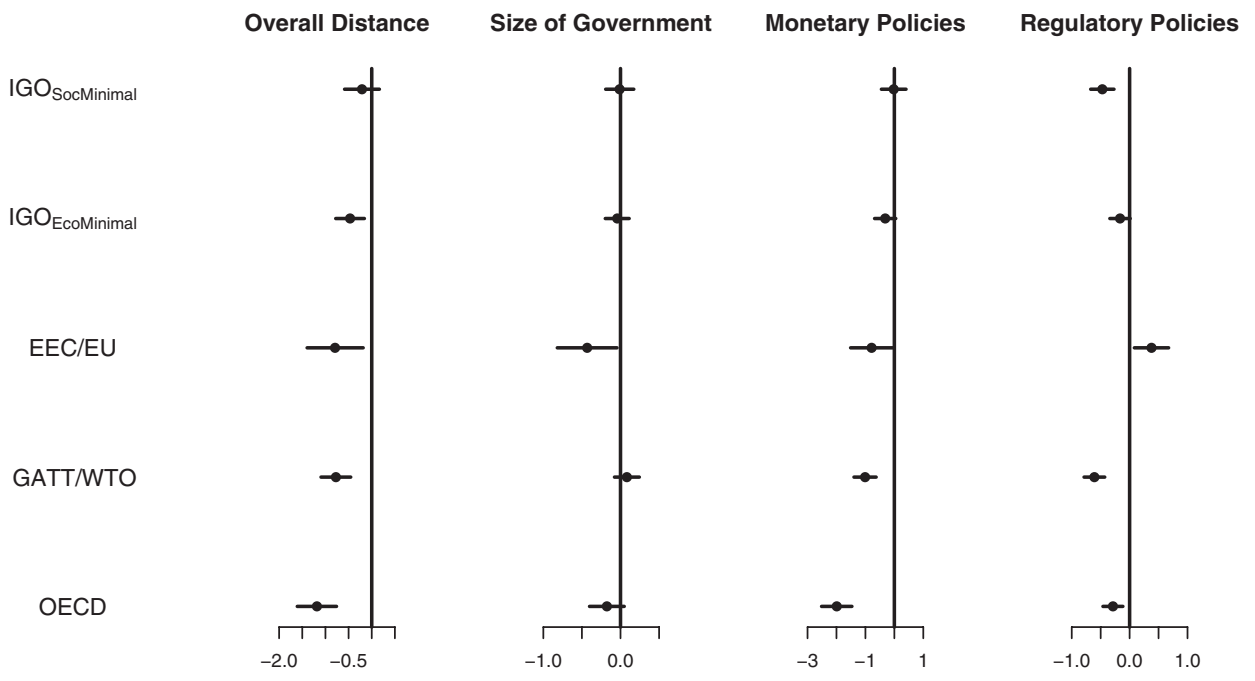

FIG 4. IGO Treatment Causal Effects on Policy Distance after Matching

GATT/WTO, and OECD all have clear negative effects. Shared membership in minimalist IGOs with social and cultural functions $\left(I_{\text {SOcial, Minimalist }}\right)$, on the other hand, has no clear causal effect on domestic economic policy convergence. This finding of no causal effect is consistent with previous findings of the lack of statistical association between $I G O_{\text {Social,Minimalist }}$ and overall policy distance. Recall that minimalist IGOs with social and cultural functions can only induce policy convergence through the mechanism of policy emulation and therefore provide a perfect test for the emulation mechanism (see Table 2) ${ }^{35}$ This finding therefore discredits the affinity-based policy emulation mechanism we proposed in earlier sections.

Moreover, we find a clear and negative effect of $I G O_{\text {Economic,Minimalist }}$ on policy distance. We know from previous discussion that in addition to policy emulation, policy learning is a potential convergence mechanism through which minimalist and economic IGOs induce policy convergence (Table 2). Therefore, if policy learning has real causal effect on policy convergence, we are expected to see a larger converging effect/coefficient from minimalist and economic IGOs that are capable of inducing both learning and emulation than that from minimalist and social-cultural IGOs that are only capable of inducing emulation. We assume that the magnitude of the converging effect (from emulation) associated with one unit of IGO connection is constant across minimalist and social-cultural IGOs and minimalist and economic IGOs. The zero causal effect of the policy emulation mechanism in minimalist and social-cultural IGOs then suggests a similar zero causal effect by policy emulation in the network of minimalist and economic IGOs. Therefore, policy convergence caused by minimalist and economic IGOs is more likely the result of the policy learning mechanism. In sum, the finding of a clear and negative effect of IGO Economic,Minimalist and that of zero causal effect of $I G O_{\text {Social,Minimalist }}$ on policy distance indicates that policy learning mechanism through multiple layers of minimalist and economic IGOs has real causal effects on convergence at the aggregate level of domestic economic policies.

Figure 4 indicates that $E E C / E U, G A T T / W T O$, and $O E C D$ all have clear negative effects on policy distance. In theory, interventionist and economic IGOs are

\footnotetext{
${ }^{35}$ Because they lack the institutional capacity to coerce member states and they do not provide relevant information that facilitates policy learning.
} 
capable of inducing policy convergence by coercion, learning, and emulation. With the homogeneous-magnitude assumption, a larger converging effect of an interventionist and economic IGO (than a minimalist and economic IGO that is in theory capable of inducing learning and emulation) suggests that in addition to the policy convergence caused by policy learning and emulation (if any), the coercion mechanism has real converging effect on policies. By comparing the mean coefficients in the first rope ladder in Figure 4, we see that the absolute values of the converging effects for EEC/EU (0.79), GATT/WTO (0.77), and OECD (1.18) are significantly larger than that of $I G O_{\text {Economic,Minimalist }}(0.46)$. This suggests that policy coercion through individual powerful IGOs has real causal effects on convergence at the aggregate level of domestic economic policies.

The second, third, and last rope ladders in Figure 4 display the $95 \%$ confidence intervals of the causal effects of $I G O_{\text {Social,Minimalist }}$ IGO Economic,Minimalist, EEC/ $E U, G A T T / W T O$, and $O E C D$ on policy distances in different policy areas. Here, we find some differences between association (Figure 2) and causation (Figure 4). Recall that in Figure 2a, we find the puzzling result that $I G O_{\text {Social,Minimalist }}$ increases policy distance for monetary policies. This is counter-intuitive because more socialization with co-member states in same IGOs should increase the chance of policy emulation and therefore reduce policy distance. Now, after matching, we find an undetermined causal effect of $I G O_{\text {Social,Minimalist }}$ on policy distance in monetary policies (see Figure 4, third rope ladder and the top row). A similar undetermined causal effect is also found between IGOSocial,Minimalist and policy distance related to the size of the government. We only find a negative causal effect of $I G O_{\text {Social,Minimalist }}$ on regulatory policy distance (Figure 4, last rope ladder, on top). Policy emulation through IGO networks, therefore, only has its impact on regulation policies. The other two main policy areas, the size of the government and monetary policies, are resilient to the affinity-based policy emulation mechanism of the IGO networks.

$I G O_{\text {Economic,Minimalist }}$ has no clear effect on policies related to the size of government (spending and taxation), and its converging effects come from its impacts on regulatory policies and monetary policies (the $p$-values for the impacts are 0.04 and 0.03 for one tail test respectively). This is also different from what we find in statistical associations. Again, policies related to the ways that government collect and spend money, what we call "the size of the government," are impervious to the influence of a socialization process of IGO networks.

In terms of the effects of the EEC/EU, its negative causal effects are evident in monetary policies and policies related to the size of government. Notice that among all the five IGO treatments, the EEC/EU is the only one that has real causal effect on the convergence of policies related to the size of government. Moreover, what is counter-intuitive here is that the EEC/EU has a positive causal effect on regulation policies. In other words, a common EEC/EU membership increases the policy distance between countries in the regulation policies of labor, capital, and business.

Finally, the negative causal effects of both the GATT/WTO and the OECD come from their impacts on monetary and regulatory policies-this is consistent with what we find in previous sections with regard to statistical associations. Recall that the GATT/WTO does not directly regulate policies in any of the three policy areas. This therefore suggests that this interventionist and economic IGO also causes policy convergence by non-coercive approach such as socializing member states by facilitating policy learning and/or emulation. ${ }^{36}$

To recap what we find in causal modeling, we move beyond the statistical associations found in previous sections and confirm converging causal effects between shared memberships in minimalist and economic IGOs $\left(I G O_{\text {Economic,Minimalist }}\right)$, joint

${ }^{36}$ However, we cannot further differentiate these two mechanisms in this large- $n$ study. 
memberships in the GATT/WTO, the EEC/EU, and the OECD on one hand, and countries' overall policy distance, on the other. We find no evidence for causal effect of policy emulation in the networks of minimalist and social-cultural IGOs (even without assuming "homogeneous magnitude" in IGO's converging effects). If we assume "homogeneous-magnitude" converging effect, we also confirm findings from previous sections by comparing the magnitudes of the converging effects associated with different types of IGOs, that is, significant and negative causal effects of minimalist and economic IGOs and interventionist and economic IGOs on policy distance provide evidence for policy learning and coercion. Digging into the level of different policy areas, we find discrepancies between statistical association and causal effects. IGO Economic,Minimalist, GATT/WTO, and OECD mostly have converging causal effects in the areas of monetary and regulation policies. $E E C / E U$, on the other hand, has its greatest impact on monetary policies and policies relating to government spending and taxation (size of the government). The converging effects of GATT/WTO in policy areas that it does not directly regulate suggests that interventionist and economic IGOs might also cause policy convergence by non-coercive approach such as policy learning and/ or emulation. ${ }^{37}$

\section{Conclusion}

We live in a world with a globalized economy where we witness more connections and interdependencies. As trade, foreign direct and portfolio investment flourish, domestic economic policies, previously considered as purely national issues, have started to take on global importance. For instance, competition policies that determine a government's decision to block a merger, tolerate a cartel, or prohibit a business practice can have a significant impact on the flow of goods and capital, and can potentially cause economic harm in countries half a world away (Economist 1998). Naturally, salient intergovernmental organizations such as the WTO, the EU, and the OECD become more and more important players. Along with nation states, they are actively involved in policy research, design, and implementation to face the new challenges of the global economy. What we have found in this study also demonstrates important roles played by these salient IGOs. Each of the three IGOs we studied has a strong converging effect on their member states' domestic economic policy configurations and these effects can be considered as causal effects even after taking account of the potential problems of endogeneity and reverse causality in empirical analysis. Moreover, we find that the WTO, the EU, and the OECD have different causal effects on different policy areas. The policy area most impervious to the forces of IGO networks, that is, policies related to the size of the government, is only subject to

\footnotetext{
37 Throughout this section, we implicitly assume that the causal effects of IGO variables on policy convergence are constant over time. This assumption might overlook some of the important institutional details of these IGOs. For instance, as one reviewer points out, the most obvious way that the EEC/EU impacts fiscal policies of member states is through the Stability and Growth Pact which was only adopted in 1997. Therefore, the causal effect of the $\mathrm{EEC} / \mathrm{EU}$ variable might also change over time. One way to appreciate better the effect of the Stability and Growth Pact is to estimate the causal effect of the EEC/EU variable for 1995 and 2000 separately: given the fact that the Stability and Growth Pact was only adopted in 1997, we should be able to observe a larger converging effect in 2000 than in 1995. We re-run the causal model on policy distance in the space of the size of the government (fiscal policies) separately for 1995 and 2000. The causal effect of the EEC/EU on policy distance in this policy area for 1995 is -0.44 with a standard error of 0.24 (the $p$-value is 0.07 ), and the causal effect for 2000 is -0.54 with a standard error of 0.31 (the $p$-value is 0.07 ). Therefore, the converging effect of the EEC/EU on fiscal policies is larger in 2000 when the Stability and Growth Pact was adopted than in 1995 when the Pact was adopted. This finding suggests that we should pay greater attention to the institutional details of major IGOs: the converging effects of these strong IGOs might change over time because these IGOs themselves might experience changes as well. However, we only have a very short time series for 1995 and 2000 (1990 is used as the lagged dependent variable for 1995). Therefore, we have to leave a more detailed study of institutional details to future analysis.
} 
the influence of a common EEC/EU membership. The converging effects of the WTO and the OECD are only evident in monetary and regulation policies. The fact that the WTO has converging effect on policy areas it does not regulate directly suggests that in addition to coercion, strong IGOs might affect the policies of their member states through non-coercive venues such as policy learning and emulation.

If the policy converging effects caused by resourceful IGOs are something we have more or less expected, a more interesting finding of this paper is that even IGOs without any institutional capacity to implement policy can have converging effects on their member states' domestic economic policies. Lacking the luxuries of strong institutional capacity to implement policies, the minimalist IGOs project their influence by providing a ground of socialization for states to exchange information and cultivate a sense of community. Cumulative effects of multiple layers of even the weakest types of IGOs might have causal effects on states' domestic policies. Indeed, we find that shared memberships in IGOs with economic functions and with the minimal level of institutional capacity are not only statistically associated with, but also have converging causal effects on, countries' domestic policies. If we hold the "homogeneous-magnitude" assumption, this finding supports the information-driven policy learning mechanism induced by IGO networks. ${ }^{38}$ The other mechanism through which the cumulative effects of IGO networks might cause convergence, that is, policy emulation based on a sense of affinity (created by minimalist IGOs of social and cultural functions), on the other hand, is not supported by our empirical analysis.

We hope that by moving beyond the usual suspects in the existing literature of economic globalization and diffusion of neo-liberal policies such as trade, capital flows, and cultural and linguistic proximities, our efforts in this study bring more attention to the IGO networks, especially those IGOs with only minimal level of resources and institutional capacity. Our findings suggest that policy learning and coercion cause convergence, but this is based on the assumption of a homogeneous magnitude in converging effect. Future research might seek to study further these two convergence mechanisms after releasing this assumption. Meanwhile, even though we are able to show that strong IGOs also socialize states to induce policy changes, future research needs to be done to differentiate further the two aspects of the IGO socialization process, that is, learning and emulation.

\section{Appendix A. Minimalist IGO Networks}

Figure A1 provides a visualization of the networks of minimalist IGOs for 1990, 1995, and 2000: the left column shows the networks composed of minimalist IGOs with economic purposes and the right column shows minimalist IGOs with social and cultural purposes. We use three-letter acronyms to represent countries (see Appendix $\mathrm{C}$ for corresponding country names). The countries are positioned in a two-dimensional space so that the distance between two countries is inversely related to their shared minimalist IGO memberships: the closer two countries are, the more relevant the IGO memberships that they share. Notice that IGO networks are "thick": the mean of the shared memberships of mini-

\footnotetext{
${ }^{38}$ We want to emphasize again that the "homogeneous-magnitude" assumption is a very strong assumption because it basically says that the converging effects of policy learning and emulation are homogeneous in magnitude per unit of IGO connection across different types of IGOs. In other words, the magnitude of the converging effect (from learning and from emulation) associated with one unit of IGO connection is constant across the three types of IGOs. Without this assumption, we can only test whether connections in minimalist and economic IGOs and interventionist and economic IGOs cause policy convergence without being able to specify particular causal mechanism(s) at work. The emulation mechanism, however, can be tested in the context of minimalist and social-cultural IGOs without holding this assumption.
} 


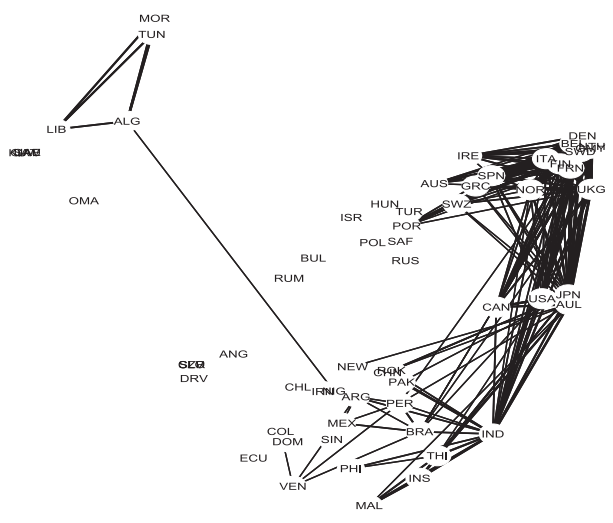

(A) Economic, minimalist, 1990

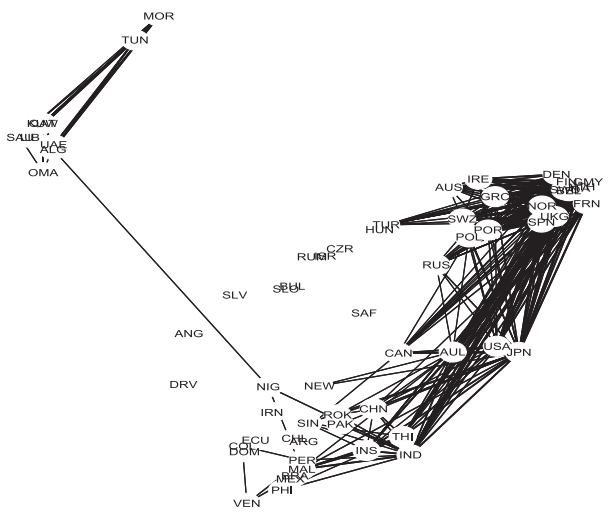

(C) Economic, minimalist, 1995

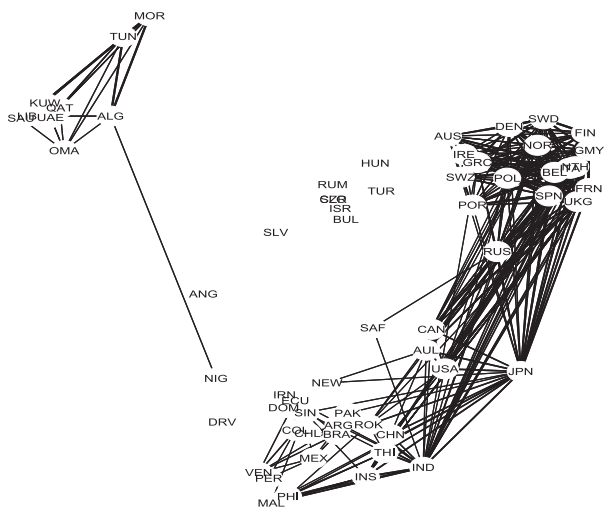

(E) Economic, minimalist, 2000

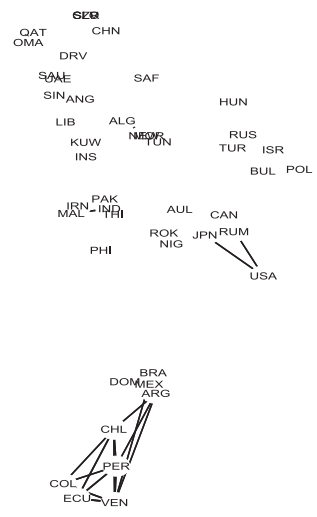

(B) Social, minimalist, 1990

SAAT
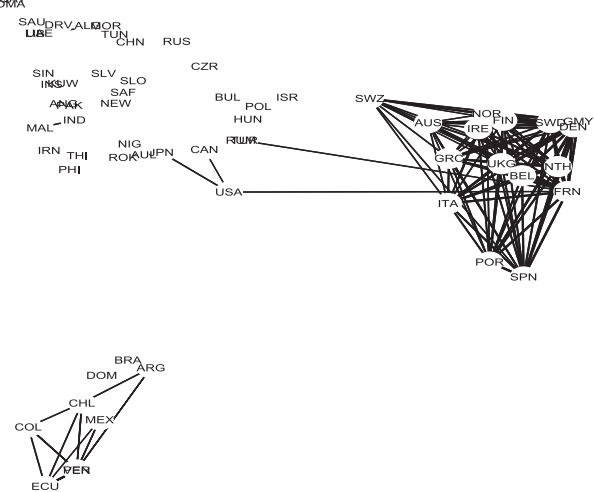

(D) Social, minimalist, 1995

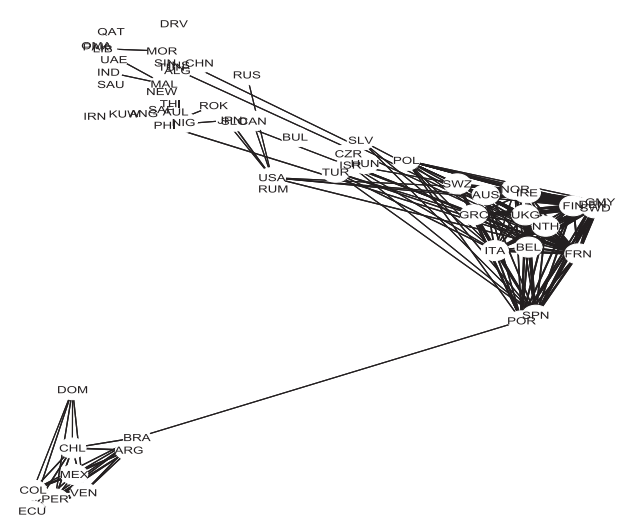

(F) Social, minimalist, 2000

FIG A1. Minimalist IGO Networks: Economic and Social

Note. IGO connections truncated by 10, that is, the graphs only display a tie if the shared IGO memberships are greater than or equal to 10. Only minimalist IGOs are included to provide better pictures for IGO networks that might cause policy learning and emulation.

malist IGOs with economic functions in 1990 is 5 and in 2000 almost 7; shared minimalist IGOs with social and cultural functions also average around 6 between 1990 and 2000. Therefore, the clustering of some countries in Fig- 
ure A1 implies dense interconnected minimalist IGO networks among these countries. To emphasize further this clustering of countries, we display a line between two countries as long as their shared minimalist IGOs (economic types for the left column and social and cultural types for the right) are greater than or equal to 10. Also, the width of the "tie" is proportional to the shared IGO memberships considered.

The first impression one might have by comparing the left column with the right column, that is, the networks with economic minimalist IGO networks to those of social/cultural minimalist IGOs, is that the networks of social/cultural minimalist IGOs are more fragmented. In 1990 (Figure A1b), three big clusters can be easily distinguished. At the right top corner, we find the group of Western European countries that are so densely connected to each other and there are so many strong ties (defined as having over 10 shared minimalist, social and cultural IGO memberships) connecting members within the cluster and there is no single strong tie connecting this Western European cluster to the other countries. The second cluster, at the lower left corner, is composed of Latin American countries. The third cluster, not as densely connected as the first two clusters, include the rest of the countries.

As time passed by, in 1995 and 2000, inter-cluster strong IGO ties started to form as we can see from Figure A1d and f. This is most evident in 2000 where the third cluster is drawn much closer to that of the Western European countries; however, the group of Latin American countries still lacks strong connections with the other two groups. If in 1990, the basic configuration of the network composed of minimalist IGOs with social and cultural functions reflects and maybe enhances geographical and cultural proximities, we observe evidence of the growth of strong connections that transcend culture and geography in later years. This suggests that IGO with minimal institutional capacity and social and cultural purposes might start to take on their own lives and serve as an arena for interactions between countries from different regions and cultural backgrounds.

The networks of minimalist IGOs with economic purposes show a lower level of clustering. Except for a small group of developing countries in Africa and the Middle East (Morocco (MOR), Tunisia (TUN), Algeria (ALG), Libya (LIB), Kuwait (KUW), etc.), the rest of the countries are close to one another. However, we still see clustering. Western European countries are closer to themselves than to other countries. But, large amounts of strong ties exist between them and the other countries. If the networks of minimalist IGOs with economic purposes are a good predictor of domestic economic convergence, we expect to observe policy convergence, although at different levels, among almost all the countries except for those African and Middle Eastern outliers.

Appendix B. Detailed dimensions of Domestic Economic Policies Size of Government: Expenditures, Taxes, and Enterprises

There are four components in this policy area indicating the extent to which countries rely on individual choice and markets rather than the political process to allocate resources, goods, and services. Specifically:

- General government consumption spending as a percentage of total consumption;

- Transfers and subsidies as a percentage of GDP;

- Government enterprises and investment as a percentage of total investment;

- Top marginal tax rate (and income threshold at which it applies): 
- Top marginal income tax rate (and income threshold at which it applies);

- Top marginal income and payroll tax rates (and income threshold at which they apply).

These policy outcomes cover the ways governments collect and spend money: they are often the indicators, though not exactly the same, for welfare state/compensation politics literature and taxation literature (Cameron 1978; Katzenstein 1985; Garrett and Lange 1989; Garrett 1998; Hallerberg and Basinger 1998; Iversen and Cusack 2000; Wibbels and Arce 2003).

\section{Access to Sound Money}

Too much money chasing too few goods invariably leads to inflation. At the same time, when the rate of inflation increases, it often becomes volatile. High and volatile inflation are detrimental to healthy economic activities as it distorts relative prices, alters the fundamental terms of long-term contracts, and therefore makes it impossible for individuals and businesses to plan the future.

- Average annual growth of the money supply in the last five years minus average annual growth of real GDP in the last 10 years;

- Standard inflation variability in the last five years;

- Recent inflation rate;

- Freedom to own foreign currency bank accounts domestically and abroad.

There are various aspects of monetary policies, and the four indicators listed above characterize some important aspects among them: the supply of money, level and stability of inflation rate, and some form of capital control for citizens.

\section{Regulation of Credit, Labor, and Business}

This is the most multifaceted policy area we considered in this research. The details are listed in the following:

- Credit market regulations:

- Ownership of banks-percentage of deposits held in privately owned banks;

- Competition-domestic banks face competition from foreign banks;

- Extension of credit-percentage of credit extended to private sector;

- Avoidance of interest rate controls and regulations that lead to negative real interest rates;

- Interest rate controls-interest rate controls on bank deposits and/or loans are freely determined by the market.

- Labor market regulations:

- Impact of minimum wage - the minimum wage, set by law, has little impact on wages because it is too low or not obeyed;

- Hiring and firing practices-hiring and firing practices of companies are determined by private contract;

- Share of labor force whose wages are set by centralized collective bargaining;

- Unemployment benefits-the unemployment benefits system preserves the incentive to work;

- Use of conscripts to obtain military personnel. 
- Business regulations:

- Price controls-extent to which businesses are free to set their own prices;

- Administrative conditions and new businesses-administrative procedures are an important obstacle to starting a new business;

- Time with government bureaucracy-senior management spends a substantial amount of time dealing with government bureaucracy;

- Starting a new business-starting a new business is generally easy;

- Irregular payments-irregular, additional payments connected with import and export permits, business licenses, exchange controls, tax assessments, police protection, or loan applications are very rare.

Appendix C. Country Names and Acronyms

Algeria (ALG), Argentina (ARG), Australia (AUL), Austria (AUS), Belgium (BEL), Brazil (BRA), Bulgaria (BUL), Canada (CAN), Chile (CHL), China $(\mathrm{CHN})$, Colombia (COL), Denmark (DEN), Dominican Republic (DOM), Ecuador (ECU), Finland (FIN), France (FRN), Germany (GMY), Greece (GRC), Hungary (HUN), India (IND), Indonesia (INS), Iran (IRN), Ireland (IRE), Israel (ISR), Italy (ITA), Japan (JPN), Korea Republic (ROK), Kuwait (KUW), Malaysia (MAL), Mexico (MEX), Morocco (MOR), Netherlands (NTH), New Zealand (NEW), Nigeria (NIG), Norway (NOR), Oman (OMA), Pakistan (PAK), Peru (PER), Philippines (PHI), Poland (POL), Portugal (POR), Romania (RUM), Russian Federation (RUS), Singapore (SIN), South Africa (SAF), Spain (SPN), Sweden (SWD), Switzerland (SWZ), Thailand (THI), Tunisia (TUN), Turkey (TUR), United Kingdom (UKG), United Arab Emirates (UAE), United States of America (USA), and Venezuela (VEN).

\section{References}

Abdelal, Rawi. (2006) Writing the Rules of Global Finance: France, Europe, and Capital Liberalization. Review of International Political Economy 13 (1): 1-27.

Andrews, David M. (1994) Capital Mobility and State Autonomy: Toward a Structural Theory of International Monetary Relations. International Studies Quarterly 38 (2): 193-218.

Barabasi, Albert-Laszlo. (2002) Linked: the New Science of Networks. Cambridge, Mass: Perseus Pub.

Basinger, Scott, and Mark Hallerberg. (2004) Remodeling the Competition for Capital: How Domestic Politics Erase the Race to the Bottom. American Political Science Review 98 (2): 361376.

Bearce, David H, and Stacy Bondanella. (2007) Intergovernmental Organizations, Socialization, and Member-State Interest Convergence. International Organization 61 (04): 703-733.

Beck, Nathaniel, and Jonathan N. Katz. (1995) What to do (and Not To Do) with Time-Series Cross-Section Data. American Political Science Review 89 (3): 634-647.

Beckfield, Jason. (2003) Inequality in the World Polity: The Structure of International Organization. American Sociological Review 68 (3): 401-424.

Berger, Susanne, And Ronald Dore. (1996) National Diversity and Global Capitalism. Ithaca, NY: Cornell University Press.

Bernhard, William, Lawrence J. Broz, and William R. Clark. (2002) The Political Economy of Monetary Institutions. International Organization 56 (4): 693-723.

Boehmer, Charles, Erik Gartzke, and Timothy Nordstrom. (2004) Do International Organizations Promote Peace? World Politics 57 (1): 1-38.

Burgoon, Brain. (2001) Globalization and Welfare Compensation: Disentangling the Ties that Bind. International Organization 55 (3): 509-551.

Burns, Lawton R., and Douglas R. Wholey. (1993) Adoption and Abandonment of Matrix Management Programs: Effects of Organizational Characteristics and Interorganizational Networks. The Academy of Management Journal 36 (1): 106-138. 
Burt, Ronald S. (1992) Structural Holes: The Social Structure of Competition. Cambridge, MA: Harvard University Press.

Calvo, Guillermo A., and Enrique G. Mendoza. (2000) The Effect of the Internet on International Trade. Journal of International Economics 51 (1): 79-113.

Cameron, David. (1978) The Expansion of the Public Economy. American Political Science Review 72 (4): 1243-1261.

Cao, Xun. (2006) Convergence, Divergence, and Networks in the Age of Globalization: A Social Network Analysis Approach to IPE. In Inaugural Meeting of the International Political Economy Society. Princeton University.

Cao, Xun, Aseem Prakash, and Michael D. Ward. (2007) Protecting Jobs in the Age of Globalization: Examining the Relative Salience of Social Welfare to Industrial Subsidies in OECD Countries. International Studies Quarterly 51 (2): 301-327.

Cerny, Philip G. (1995) Globalization and the Changing Logic of Collective Action. International Organization 49 (4): 595-625.

Chinn, Menzie D., And Hiro Ito. (2006) What Matters for Financial Development? Capital Controls, Institutions, and Interactions. Journal of Development Economics 81 (1): 163-192.

CIA. (2004) The World Factbook. Central Intelligence Agency. Available at http://www.cia.gov/cia/ publications/factbook/fields/2122.html. (Accessed March 22, 2006.)

Darr, Eric D., Linda Argote, and Dennis Epple. (1995) The Acquisition, Transfer, and Depreciation of Knowledge in Service Organizations: Productivity in Franchises. Management Science 41 (11): 1750-1762.

Davis, Gerald F. (1991) Agents without Principles? The Spread of the Poison Pill through the Intercorporate Network. Administrative Science Quarterly 36 (4): 583-613.

DiMaggio, Paul J., and Hugh Louch. (1998) Socially Embeded Consumer Transactions: For What Kind of Purchases Do People Use Networks Most? American Sociological Review 63: 619-637.

Elkins, Zachary, Andrew T. Guzman, and Beth A. Simmons. (2006) Competing for Capital: The Diffusion of Bilateral Investment Treaties, 1960-2000. International Organization 60 (4): 811-846.

Everitt, Brian S., and Graham Dunn. (2001) Applied Multivariate Data Analysis. New York, NY: Oxford University Press.

Feenstra, Robert C., Robert E. Lipsey, Haiyan Deng, Alyson C. Ma, and Hengyong Mo. (2005) World Trade Flows: 1962-2000. Working Paper 11040 National Bureau of Economic Research Cambridge, MA, USA.

Finnemore, Martha. (1993) International Organizations as Teachers of Norms: The United Nations Educational, Scientific, and Cultural Organization and Science Policy. International Organization 47 (4): 565-597.

Frank, David John. (1997) Science, Nature, and the Globalization of the Environment, 1870-1990. Social Forces 76 (2): 409-435.

Friedman, Thomas L. (2000) The Lexus and the Olive Tree. New York: Anchor Books.

Garrett, Geoffrey. (1998) Partisan Politics in the Global Economy. New York: Cambridge University Press.

Garrett, Geoffrey, and Barry Weingast. (1993) Ideas, Interests and Institutions: Constructing the European Community's Internal Market. In Ideas and Foreign Policy, edited by Judith Goldstein and Robert Keohane. Ithaca, NY: Cornell University Press, 173-206.

Garrett, Geoffrey, and Deborah Mitchell. (2001) Globalization and the Welfare State. European Journal of Political Research 39 (2): 145-177.

Garrett, Geoffrey, and Peter Lange. (1989) Government Partisanship and Economic Performance: When and How Does 'Who Governs' Matter? Journal of Politics 51 (3): 676-693.

Gartzke, Erik, James D. Gwartney, and Robert A. Lawson. (2005) Economic Freedom of the World: 2005 Annual Report. Vancouver, Canada: Fraser Institute.

Goldstein, Judith L., Douglas Rivers, and Michael Tomz. (2007) Institutions in International Relations: Understanding the Effects of the GATT and the WTO on World Trade. International Organization 61 (1): 37-67.

Granovetter, Mark. (1985) Economic Action and Social Structure: The Problem of Embededness. American Journal of Sociology 91: 481-510.

Gruber, Lloyd. (2000) Ruling the World: Power Politics and the Rise of Supranational Institutions. Princeton, NJ: Princeton University Press.

Guler, Isen, Guillen Mauro, and MacPherson John M. (2002) Global Competition, Institutions, and Organizational Change: The International Diffusion of the ISO 9000 Quality Standards. Administrative Science Quarterly 47: 207-232. 
Hall, Peter, and David Soskice. (2001) Varieties of Capitalism: The Institutional Foundations of Comparative Advantage. Oxford: Oxford University Press.

Hallerberg, Mark, And Scott Basinger. (1998) Internationalization and Changes in Tax Policy in OECD Countries: The Importance of Domestic Veto Players. Comparative Political Studies 31 (3): 321-352.

Henisz, Witold J., Bennet A. Zelner, and Mauro F. Guillén. (2005) The Worldwide Diffusion of Market-Oriented Infrastructure Reform, 1977-1999. American Sociological Review 70 (6): 871-897.

Ho, Daniel E., Kosuke Imai, Gary King, and Elizabeth A. Stuart. (2004) Matching as Nonparametric Preprocessing for Reducing Model Dependence in Parametric Causal Inference. Working paper at Gking.Harvard.Edu/matchit. (Accessed March 2007.)

Imai, Kosuke, and David A. van Dyk. (2004) Causal Inference With General Treatment Regimes: Generalizing the Propensity Score. Journal of the American Statistical Association 99 (467): 854-866.

Ingram, Paul. (2005) Interorganizational Learning. In The Blackwell Companion to Organizations, edited by Joel A. C. Baum. Oxford: Blackwell Publishing.

Ingram, Paul, Jeffrey Robinson, and Marc L. Busch. (2005) The Intergovernmental Network of World Trade: IGO Connectedness, Governance, and Embeddedness. American Journal of Sociology 111 (3): 824-858.

Iversen, Torben, and Thomas R. Cusack. (2000) The Causes of Welfare State Expansion: De-industrialization or Globalization? World Politics 52 (3): 313-349.

Johnston, Alastair I. (2001) Treating International Institutions as Social Environments. International Studies Quarterly 45 (4): 487-515.

Katzenstein, Peter J. (1985) Small States in World Markets: Industrial Policy in Europe. Ithaca, NY: Cornell University Press.

Keohane, Robert O. (1984) After Hegemony: Cooperation and Discord in the World Political Economy. Princeton, NJ: Princeton University Press.

Kitschelt, Herbert. (2001) Partisan Competition and Welfare State Retrenchment: When Do Politicians Choose Unpopular Policies? In The New Politics of Welfare State, edited by Paul Pierson. Oxford: Oxford University Press.

KraAtz, Matthew S. (1998) Learning by Association? Interorganizational Networks and Adaptation to Environmental Change. The Academy of Management Journal 41 (6): 621-643.

Krasner, Stephen D. (1983) International Regimes. Ithaca, NY: Cornell University Press.

Lee, Chang Kil, and David Strang. (2006) The International Diffusion of Public-Sector Downsizing: Network Emulation and Theory-Driven Learning. International Organization 60 (4): 883-909.

Mearsheimer, John J. (1994) The False Promise of International Institutions. International Security 19 (3): $5-49$.

Meyer, John W., Francisco O. Ramirez, and Yasemin Nuhoglu Soysal. (1992) World Expansion of Mass Education, 1870-1980. Sociology of Education 65 (2): 128-149.

Mosley, Layna. (2000) Room to Move: International Financial Markets and National Welfare States. International Organization 54 (4): 737-773.

Nemeth, Roger, And David A. Smith. (1985) International Trade and World-System Structure: A Multiple Network Analysis. Review (Fernand Braudel Center) 8: 517-560.

North, Douglass C. (1990) Institutions, Institutional Change and Economic Performance. Cambridge, UK: Cambridge University Press.

Pevehouse, Jon, Timothy Nordstrom, and Kevin Warnke. (2003) Intergovernmental Organizations, 1815-2000: A New Correlates of War Data Set. Available at http://www.correlatesofwar.org. (Accessed on June 1, 2006.)

Plümper, Thomas, and Vera E. Troeger. (2007) Efficient Estimation of Time-Invariant and Rarely Changing Variables in Finite Sample Panel Analyses with Unit Fixed Effects. Political Analysis 15 (2): 124-139.

Polillo, Simone, and Mauro F. Guillén. (2005) Globalization Pressures and the State: The Worldwide Spread of Central Bank Independence. American Journal of Sociology 110 (6): 1764-1802.

Prakash, Aseem, and Matthew Potoski. (2007) Investing Up: FDI and the Cross-Country Diffusion of ISO 14001 Management Systems1. International Studies Quarterly 51 (3): 723-744.

Rodrik, Dani. (1997) Has Globalization Gone Too Far? Washington, DC: Institute for International Economics.

Rosenbaum, Paul R., and Donald B. Rubin. (1983) The Central Role of the Propensity Score in Observational Studies for Causal Effects. Biometrika 70 (1): 41-55.

Rubin, Donald B. (1974) Estimating Causal Effects of Treatments in Randomized and Nonrandomized Studies. Journal of Educational Psychology 66 (5): 688-701. 
Shambaugh, Jay. (2004) Exchange Rate Regime Clacification Data Set. Available at http://www. dartmouth/edu/ jshambau/. (Accessed March 10, 2008.)

Simmons, Beth A., Frank Dobbin, and Geoffrey Garrett. (2006) Introduction: The International Diffusion of Liberalism. International Organization 60 (4): 781-810.

Simmons, Beth A., And Zachary Elkins. (2004) The Globalization of Liberalization: Policy Diffusion in the International Economy. American Political Science Review 98 (1): 171-189.

Smith, David A., and Douglas R. White. (1992) Structure and Dynamics of the Global Economy: Network Analysis of International Trade 1965-1980. Social Forces 70 (4): 857-893.

Snyder, David, and Edward L. Kick. (1979) Structural Position in the World System and Economic Growth, 1955-1970: A Multiple-Network Analysis of Transnational Interactions. American Journal of Sociology 84 (5): 1096-1126.

Strang, David, and Patricia Mei Yin Chang. (1993) The International Labor Organization and the Welfare State: Institutional Effects on National Welfare Spending, 1960-80. International Organization 47 (2): 235-262.

The Economist. (1998) The Borders of Competition. The Economist 348: 69-70.

Uzzi, Brian. (1996) The Sources and Consequences of Embedness for the Economic Performance of Organizations: The Network Effect. American Sociological Review 61: 674-698.

Watts, Duncan J. (1999) Small Worlds: The Dynamics of Networks between Order and Randomness. Princeton, NJ: Princeton University Press.

Wibbels, Erik, And Moisés Arce. (2003) Globalization, Taxation, and Burden-Shifting in Latin America. International Organization 57 (4): 111-136.

Zahariadis, Nikolaos. (1997) Why State Subsidies? Evidence from European Community Countries, 1981-86. International Studies Quarterly 41 (2): 341-354.

Zahariadis, Nikolaos. (2001) Asset Specificity and State Subsidies in Industrial Countries. International Studies Quarterly 45 (4): 603-616. 